\title{
La transición de los Objetivos de Desarrollo del Milenio a los Objetivos de Desarrollo Sostenible desde la perspectiva de los determinantes sociales de la salud y la equidad en salud
}

\author{
Manuel Urbina-Fuentes' ${ }^{1}$, Luis Jasso-Gutiérrez², Raffaela Schiavon-Ermani, Rafael Lozano ${ }^{4}$ \\ y Jacobo Finkelman ${ }^{5}$ \\ ${ }^{1}$ Coordinador del Comité Permanente para el Estudio de los Determinantes Sociales de la Salud, Academia Nacional de Medicina; ${ }^{2}$ Academia \\ Nacional de Medicina; ${ }^{3}$ Consultora independiente, ex Directora General de Ipas México AC; ${ }^{4}$ Instituto Nacional de Salud Pública (CISS); ${ }^{5} \mathrm{Consultor}$ \\ independiente en temas relacionados con la salud pública y ambiental. México
}

\begin{abstract}
Resumen
La Declaración de la Organización de las Naciones Unidas del año 2000 acordó ocho Objetivos de Desarrollo del Milenio (ODM) para cumplir en 2015. Los resultados muestran que la pobreza continúa por el incremento poblacional, y los avances tanto en los países ricos como en los pobres son amenazados por crisis económicas e inequidades en áreas geográficas y grupos de población dentro de los países. En un mundo globalizado, con grandes desigualdades sociales y económicas, desde la perspectiva de los determinantes sociales de la salud (DSS), la relevancia de los nuevos 17 Objetivos de Desarrollo Sostenible (ODS) es mayor. Ante los desafíos en salud que se enfrentan en nuestro país para lograr los ODS se presentó, en el XLIV Congreso Nacional de la Academia, el Simposio La transición de Ios ODM a los ODS desde la perspectiva de los DSS y la equidad en salud. Las ponencias abordaron cinco aspectos relevantes en la transición en México: antecedentes y contexto; estado actual de los ODM en la niñez; impacto sobre la equidad de género y la fecundidad adolescente; y sistema de salud y salud ambiental; presentados por los doctores Raffaela Schiavon, Jacobo Finkelman, Luis Jasso y Rafael Lozano.
\end{abstract}

PALABRAS CLAVE: Objetivos de Desarrollo del Milenio. Objetivos de Desarrollo Sostenible. Determinantes sociales de la salud. Equidad en salud. Inequidades. Desigualdades.

\begin{abstract}
The United Nations Declaration of 2000 agreed on eight millennium development goals (MDGs) to be met in 2015. The results show that poverty continues through population growth and advances in both rich and poor countries are threatened by economic crises and inequities in geographic areas and population groups within countries. In a globalized world with great social and economic inequalities, from the perspective of the social determinants of health (SDH), the relevance of the new 17 sustainable development goals (SDGs) is greater. Faced with the health challenges in our country to achieve SDGs, the symposium "The transition from MDGs to SDGs from the perspective of SDH and health equity" was presented at the XLIV Congress of the National Academy of Medicine. The presentations dealt with five important aspects of the transition in Mexico: background and context; the current state of the MDGs in childhood; the impact on gender equity and adolescent fertility; the health system and the theme of environmental health and were presented by Dr. Raffaela Schiavon, Jacobo Finkelman, Luis Jasso and Rafael Lozano.
\end{abstract}

KEY WORDS: Millennium Development Goals. Sustainable Development Goals. Social determinants of health. Equity in health. Inequities. Inequalities.

\author{
Correspondencia: \\ Manuel Urbina Fuentes \\ Málaga, 88 \\ Col. Insurgentes Mixcoac \\ C.P. 03920, Ciudad de México, México \\ E-mail: murbina@insad.com.mx
}

Fecha de recepción: 01-10-2016

Fecha de aceptación: 05-10-2016

DOI:10.24875/GMM.M17000017
Gac Med Mex. 2017;153:697-730

Contents available at PubMed www.gacetamedicademexico.com 


\section{Introducción}

La Declaración del Milenio de la Organización de las Naciones Unidas (ONU), adoptada en el año 2000, ofreció un marco amplio de valores, principios para la paz y la seguridad, el desarrollo y los derechos humanos. Se acordó alcanzar ocho Objetivos de Desarrollo del Milenio (ODM), con metas e indicadores cuantitativos para cumplir en el año 2015. Los ODM se convirtieron en un marco de referencia mundial para avanzar en su logro, y la experiencia adquirida demostró que para obtener progresos sustanciales deben incorporarse a las estrategias nacionales de desarrollo y contar con un sistema de seguimiento para ajustar las políticas de acuerdo con su impacto efectivo.

A tres lustros de su inicio, los resultados muestran pocos progresos en la reducción de la pobreza y el retroceso en la disminución de las desigualdades, principalmente en las naciones con economías emergentes; persisten las inequidades entre países, así como entre áreas geográficas y grupos de población dentro de los países, como es el caso del empleo para las mujeres, la mortalidad infantil y materna, y en el ámbito de la sostenibilidad medioambiental, la deficiencia energética y la escasez del agua y de los alimentos ${ }^{1}$.

La pobreza continúa por el incremento anual de la población; ya somos 7500 millones y los avances alcanzados son amenazados por las crisis económicas. Otros desafíos, como la calidad de la educación primaria, la falta de representación de las mujeres en puestos de toma de decisiones, el acceso desigual a la atención primaria de la salud y la salud reproductiva, el aumento de la prevalencia del virus de la inmunodeficiencia humana (VIH) y la tuberculosis; el saneamiento en las zonas rurales, los asentamientos informales en crecimiento y la migración involuntaria por conflictos bélicos repercuten en lograr los ODM para los grupos socialmente excluidos. El hecho de que los ODM fijados para todo el mundo han sido difíciles de alcanzar para un número significativo de países demuestra la relevancia del cambio que ahora tienen los nuevos Objetivos de Desarrollo Sostenible (ODS), que son más ambiciosos que los ODM y, por lo tanto, más desafiantes en un mundo globalizado con grandes desigualdades sociales y económicas, tanto en países ricos como en países pobres².

Los ODS incluyen la universalidad y la indivisibilidad, y el compromiso de no dejar atrás a nadie, con procesos participativos, transparentes y basados en los derechos humanos, y la responsabilidad de presentar informes, en particular dar especial atención a los más pobres, vulnerables y atrasados. Los ODS son 17 y tienen 169 metas que se proponen alcanzar y medir a través de 231 indicadores que se han comprometido a cumplir 143 países, lo que muestra la gran escala y la ambición de la Nueva Agenda Universal, en vigor desde enero de 2016 y hasta el año 2030. Los objetivos se implementarán desde los niveles global, multilateral, regional, nacional y local, y buscan poner fin a la pobreza en todas sus formas, reducir la desigualdad y luchar contra el cambio climático; se exige que las tres dimensiones que abarcan, económica, social y ambiental, se aborden de manera integrada ${ }^{3}$.

Debido a la importancia que tienen los ODS, desde la perspectiva de los determinantes sociales de la salud (DSS) y ante los desafíos en salud que se enfrentan en nuestro país para lograr la equidad en salud, como Coordinador del Comité permanente para el estudio de los DSS de nuestra corporación, presento aquí los temas de controversia que se trataron en el XLIV Congreso Nacional en el Simposio La transición de los Objetivos de Desarrollo del Milenio a los Objetivos de Desarrollo Sostenible desde la perspectiva de los determinantes sociales de la salud y la equidad en salud.

\section{Antecedentes y Contexto}

En la transición de 8 ODM a 17 ODS, para poder abordarlos de manera integrada se afrontarán varios desafíos en las tres dimensiones que abarcan, la económica, la social y la ambiental, porque valorar los logros o las injusticias sociales que disfruta o padece la población de un país, de un Estado o de un municipio y sus localidades implica observar no solo sus condiciones de salud, alimentación, educación, vivienda y empleo, sino también la situación de las desigualdades 0 inequidades, es decir, las diferencias consideradas como indignas, remediables y evitables 4 .

Asimismo, debido a que las políticas públicas con planes y programas de tipo económico, social y cultural no han considerado a los DSS como causas de las inequidades o desigualdades, en el caso de la inequidad en salud esta se profundiza por tres megatendencias: 1) la transición demográfica y epidemiológica, 2) la migración y 3) el crecimiento urbano acelerado 5 .

En el caso de la equidad en salud, esta se puede alcanzar a través de políticas públicas coordinadas y 
un financiamiento adecuado. Sin embargo, como resultado de la transición demográfica, en las últimas cuatro décadas se ha tenido un incremento poblacional mundial de 3000 millones, con un promedio anual de 80 millones de personas, por lo que actualmente somos 7,500 millones de habitantes y ya se proyecta que llegaremos a 10,000 millones en el año 2056, 6 años antes de lo estimado anteriormente. Debido a que el crecimiento demográfico se ha dado principalmente en los países en vías de desarrollo, se ha creado incertidumbre en la gestión de los recursos por el aumento en la demanda de agua, energía y alimentos, así como por los efectos en el cambio climático, los fenómenos meteorológicos y los cambios irreversibles que estos conllevan 6 . Ante tales hechos, diferentes investigadores y organizaciones especializadas han planteado que, para contar con un espacio operativo seguro para la humanidad y un desarrollo económico inclusivo y sostenible, hay nueve límites planetarios: 1) cambio climático; 2) uso del agua; 3) ciclos del nitrógeno y del fósforo; 4) acidificación oceánica; 5) contaminación química; 6) carga atmosférica de aerosoles; 7) agotamiento del ozono; 8) pérdida de la biodiversidad; y 9) cambio del uso de la tierra. Los han denominado «el techo ambiental o ecológico» que al no ser rebasado permita contar con una base social segura para proteger el agua, los ingresos, la educación, la resiliencia, el trabajo, la energía, la igualdad social, la equidad de género, la salud y los alimentos ${ }^{7}$.

Preocupa que ya son cuatro de los nueve límites planetarios los más afectados: el cambio climático, los ciclos del nitrógeno y del fósforo, la pérdida de biodiversidad y la conversión de la tierra; y están por cuantificarse dos más: la contaminación del aire y la contaminación química ${ }^{8}$ (Fig. 1).

\section{La era del desarrollo sostenible y los riesgos globales}

El Dr. Jeffrey D. Sachs ${ }^{9}$ explica que la era del desarrollo sostenible es un concepto central de nuestra época, que se debe entender en el mundo y ver como un método para resolver los problemas globales y tratar de dar sentido a las interacciones de tres sistemas complejos: 1) la sociedad global, 2) la economía mundial y 3) el medio ambiente físico de la Tierra. Asimismo, serán los más afectados en la era del desarrollo sostenible.

La evidencia indica que la Tierra sufrirá un calentamiento de $1.5^{\circ} \mathrm{C}$, superior a los niveles preindustriales, que dará un aumento de más de $30 \mathrm{~cm}$ en el nivel del mar para el año 2100, que habrá sequías más severas y que casi el $90 \%$ de los arrecifes de coral estarán en riesgo de extinción. Los fenómenos meteorológicos extremos afectan la vida en todo el mundo, dañando los cultivos y las costas, y poniendo en peligro la seguridad hídrica. Se identifica que hasta 849 millones de hectáreas de terrenos naturales (casi el tamaño del Brasil) sufren riesgo de degradación de aquí al año 2050 si continúan las tendencias actuales de uso insostenible de la tierra. Alimentar a un número creciente de personas provoca que cada
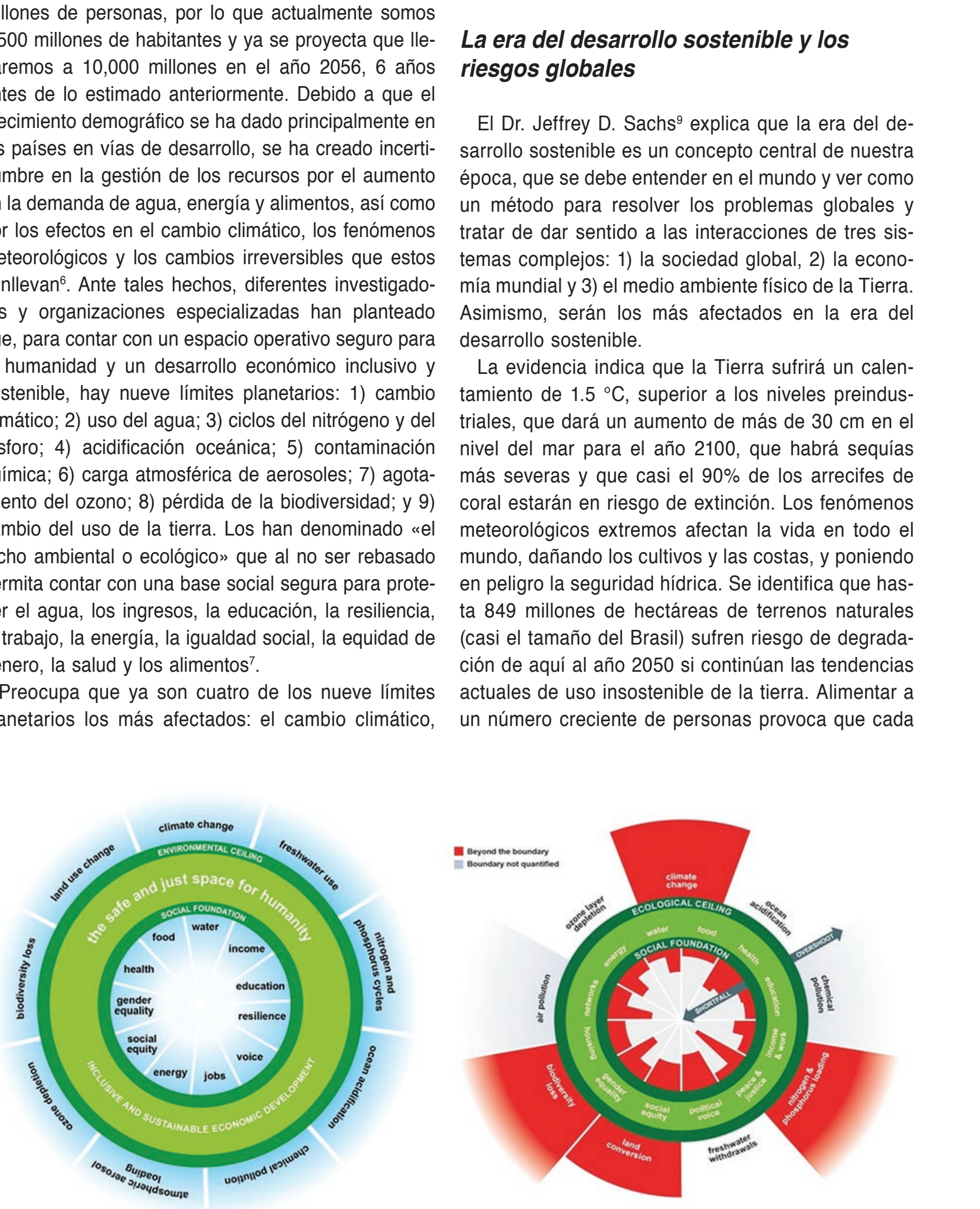

Figura 1. Los nueve límites del espacio operativo seguro para la humanidad. 
vez más terrenos se conviertan en tierras de cultivo a expensas de las sabanas, las praderas y los bosques. El resultado ha sido la degradación ambiental generalizada y la pérdida de diversidad biológica, que afectan al $23 \%$ del suelo mundial.

A lo anterior se suman los diez «riesgos globales» que el Foro Económico de Davos ha identificado en términos de probabilidad e impacto sobre la población mundial, categorizándolos en cinco áreas: 1) económica, 2) ambiental, 3) geopolítica, 4) social y 5) tecnológica. Destacan por su impacto la falla en el control y la adaptación del cambio climático; las armas de destrucción masiva; la crisis del agua; la migración involuntaria masiva; la crisis en los precios de la energía; la pérdida de la biodiversidad y el colapso de los ecosistemas; las crisis financieras; la propagación de enfermedades infecciosas; la burbuja de activos financieros; y la inestabilidad social profunda $^{10}$.

En este contexto, la Fundación Rockefeller y la revista The Lancet han organizado la Comisión sobre la salud del planeta como una nueva disciplina de la salud global, y han hecho estudios que pronostican que entre 2030 y 2050 pueden perderse 250,000 vidas anualmente por el cambio climático, ya que el $40 \%$ de la población mundial estará viviendo un grave estrés hídrico; que se desperdician al año 1 a 2,3 millones de hectáreas agrícolas por la degradación del suelo; que ocurren 300,000 muertes al año por el humo de los incendios; que el mal uso de la tierra contribuye al aumento del paludismo; y que el consumo elevado de pescados y mariscos ha provocado el $90 \%$ de la sobreexplotación en las aguas marinas $^{11}$.

\section{Las desigualdades sociales}

En el escenario mundial, por otra parte, dominan las desigualdades drásticas e involucran a todos, a los países ricos y pobres por igual. La Organización Mundial de la Salud (OMS), desde el año 2005, cuestionó por qué no se habían logrado políticas sociales más equitativas, socialmente más justas y operativamente con servicios más eficientes para lograr la equidad en salud a través de una cobertura y un aseguramiento universal. La respuesta es porque se invierte poco en salud y en otros programas sociales, como educación, vivienda y empleo; porque lo que se tiene se gasta todo en infraestructura y con elevados gastos de administración; y porque no evaluamos el desempeño y el impacto de lo que hacen los sectores responsables de las políticas sociales ${ }^{12}$.
Según el Informe Mundial de Desarrollo, la desigualdad se debe a que en esta región hay más multimillonarios que en otras zonas del mundo. La crisis mundial aumentó las desigualdades y el número de personas que vive en la pobreza ${ }^{13}$.

\section{Los determinantes sociales de las inequidades en salud}

La OMS, en respuesta a estos planteamientos y a los problemas de las desigualdades en salud y su impacto local, así como por los efectos derivados de la crisis económica en los sistemas de bienestar, enfatizó que deben analizarse las «causas de las causas» de las desigualdades en salud, e identificó como marco conceptual a los «determinantes estructurales e intermedios» (Fig. 2).

La OMS ha determinado que el estado de salud y el bienestar de la población dependen de los DSS, que define como «las condiciones en que las personas nacen, crecen, se alimentan, viven, se educan, trabajan, se divierten, envejecen y mueren», y del «tipo de sistemas que se utilizan para combatir la enfermedad». A su vez, «las condiciones en que la gente vive y muere están determinadas por fuerzas políticas, sociales y económicas» (determinantes estructurales), en las que influyen, según la edad y el sexo, los estilos de vida y las actitudes y las conductas de riesgo que afectan su salud (determinantes intermedios). Estas condiciones intervienen y condicionan la salud, el riesgo de enfermar, la posibilidad de rehabilitarse y el impacto en la esperanza de vida ${ }^{14}$. Asimismo, ante la creciente preocupación suscitada por estas inequidades persistentes, y cada vez mayores, en todos los países miembros de la OMS, en el año 2005 se creó la Comisión sobre Determinantes Sociales de la Salud para ofrecer opciones y asesoramiento respecto a la manera de mitigarlas. En el informe final de la Comisión, presentado el Profesor Sir Michael Marmot en agosto de 2008, se propusieron tres recomendaciones generales: 1) mejorar las condiciones de vida cotidiana; 2) luchar contra la distribución desigual del poder, el dinero y los recursos; y 3) medir y analizar el problema. Estas recomendaciones para lograr la equidad en salud, y la adopción de las intervenciones para implementarlas, se ratificaron por jefes de Estado, ministros y representantes de gobiernos, en el año 2011, con la Declaración Política de Río sobre Determinantes Sociales de la Salud mediante la actuación sobre los determinantes sociales de 


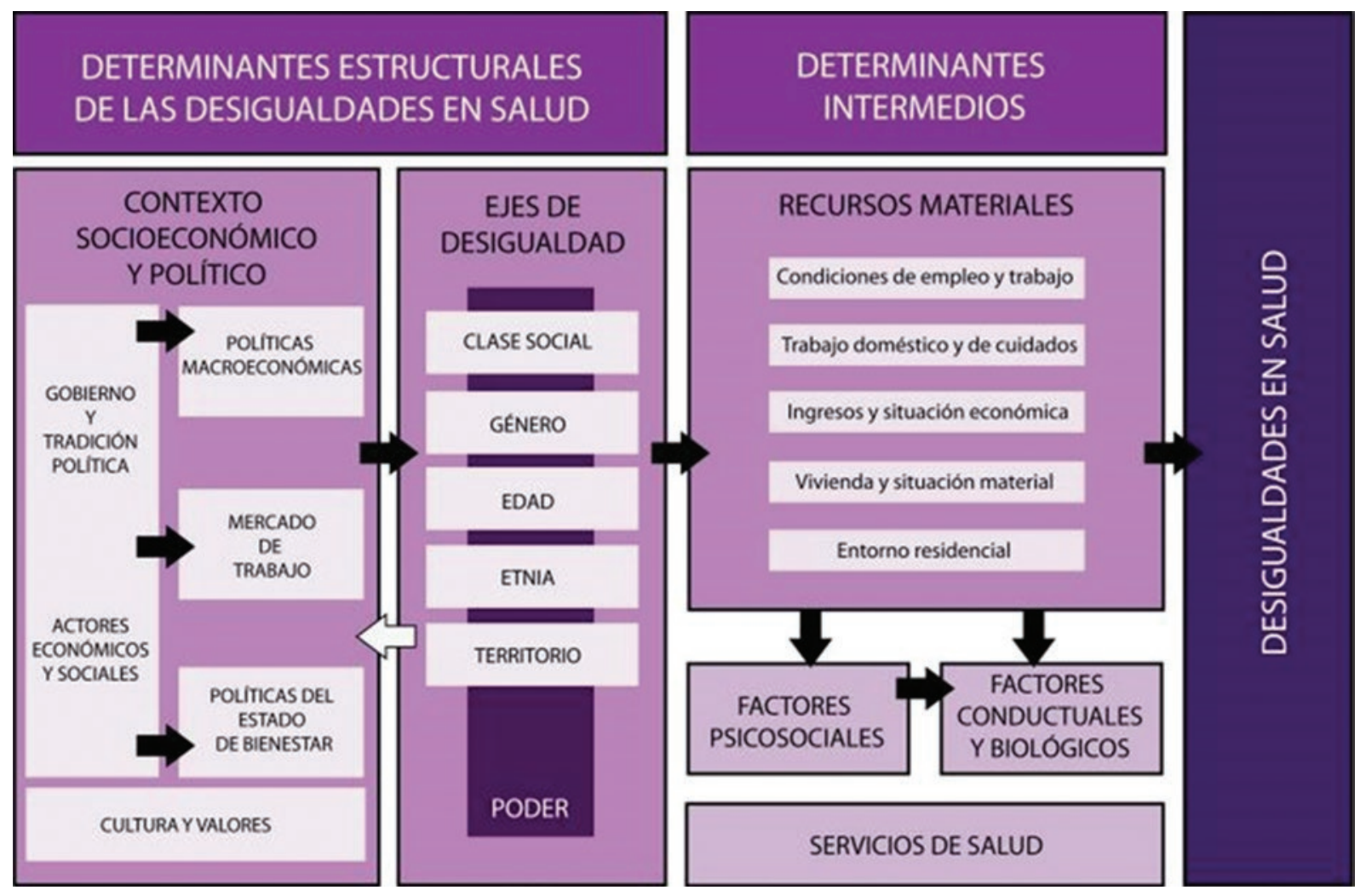

Figura 2. Determinantes estructurales e intermedios de las desigualdades en salud ${ }^{14}$.

la salud y del bienestar, aplicando un enfoque intersectorial integral ${ }^{15,16}$.

\section{Los desafíos que se enfrentan en México para un desarrollo sostenible}

Adicionales, y como consecuencia del crecimiento poblacional, son varios los desafíos para lograr los ODS, porque los enfrentaremos globalmente y como país: la vulnerabilidad, la resiliencia, las diferencias en las clases sociales y la pobreza.

La vulnerabilidad es el riesgo de que ante las crisis se deterioren las capacidades y los logros de las personas, así como la capacidad de lidiar o adaptarse ante una crisis (resiliencia). En el Informe sobre Desarrollo Humano, en el que se plantea la importancia de sostener el desarrollo humano, se identifica como necesario reducir vulnerabilidades y construir resiliencia. Se analiza quiénes son vulnerables, a qué y por qué:

- ¿Quiénes son? Los pobres, los trabajadores informales socialmente excluidos, las mujeres, las personas con discapacidad, los migrantes, las minorías étnicas, los niños, los jóvenes, las personas adultas, y comunidades y regiones enteras.

- ¿A qué? A las crisis económicas y sanitarias, los desastres naturales, el cambio climático, los peligros industriales, los conflictos sociales y políticos, y los disturbios civiles.

- ¿Por qué? Por capacidades limitadas, ubicación, posición en la sociedad, períodos sensibles del ciclo de vida, poca cohesión social, instituciones poco receptivas y gobernanza deficiente.

Asimismo, las desigualdades están empeorando y menos gente que nunca es consciente de ello y de que el crecimiento poblacional desordenado las magnifica. Las clases sociales configuran no solo los resultados, sino también las oportunidades de salud, ya que las sitúa en posiciones desiguales de poder, prestigio y acceso a los recursos y servicios de salud. Las personas experimentan una exposición y una vulnerabilidad diferentes ante factores que ponen en riesgo su salud ${ }^{17}$.

La pobreza y la pobreza extrema son los otros desafíos que afectan de manera creciente a la población del país. En México, el CONEVAL, en la medición de la pobreza multidimensional de 2014, estimó que hay 55.3 millones de pobres (46.2 \%) y que, de estos, 11.4 millones son pobres extremos (9.5\%). El 
porcentaje de personas en pobreza según grupos de edad es alarmante, en particular en los menores de 18 años, de los que son pobres 21.4 millones (42.3\%) y pobres extremos 2.4 millones (11.5\%), y los de 65 años o más, que son 4.2 millones $(45.9 \%)^{18}$.

En los 100 municipios con mayor marginación, predominantemente indígenas, un millón de mexicanos son los más pobres del país, la mayor parte en Chiapas $(30 \%)$, Oaxaca (20\%), Guerrero (17\%) y Veracruz (15\%). Adicionalmente, las niñas y los niños con riesgo de morir antes de cumplir 1 año es 1.7 veces mayor que el promedio nacional; la esperanza de vida de las mujeres alcanza 51 años y la de los hombres 49 años, siendo el promedio nacional de 77.4 y 72.6 años, respectivamente. Las desigualdades de género son marcadas: 2.5 millones más de mujeres que hombres viven en condiciones de pobreza. Hay 8 millones más de mujeres que hombres que trabajan y no cuentan con seguro médico ni derecho a una pensión. En el país, el $6.9 \%$ de la población mayor de 15 años no sabe leer ni escribir: el $5.6 \%$ de los hombres y el $8.1 \%$ mujeres. El $32.5 \%$ de la población indígena mayor de 15 años es analfabeta, y triplica al del hombre indígena ${ }^{19}$.

En contraste con la pobreza, las mejoras en la salud física a lo largo del siglo pasado y el actual se ha visto que mejoran las tasas de mortalidad, como la mortalidad materna. Los problemas de salud afectan a la sociedad como un todo, y no solo a un pequeño segmento aislado. La pobreza es uno de los principales desafíos para el desarrollo global y ningún grupo es inmune a los riesgos entre los pobres, los sin hogar, los desempleados, las personas con bajo nivel de educación, las víctimas de la violencia, los migrantes y refugiados, las poblaciones indígenas, los niños y adolescentes, las víctimas de abusos, las mujeres y los ancianos abandonados ${ }^{20}$.

Debido a que la respuesta del gobierno de nuestro país fue reservada y no se implementaron políticas públicas al respecto, a pesar de haber aceptado las resoluciones de la OMS y de la ONU, desde el año 2009 la Academia Nacional de Medicina (ANM) ha tomado la iniciativa de posicionar el tema con la creación del Comité Permanente para el Estudio de los Determinantes Sociales de Salud en México (CPEDSS), y ha organizado eventos académicos, como simposios internacionales, para dar los elementos integradores de las propuestas nacionales e internacionales sobre simposios de la ANM y publicaciones de postura y específicas sobre las políticas públicas y los DSS ${ }^{21}$.

\section{Estado actual en 2015 de los Objetivos del Milenio en México con especial énfasis en la niñez}

Los DSS provocan que los individuos enfermen y mueran en mayor proporción que las poblaciones en condiciones más favorables. En los niños, su análisis debe incluir el derecho a la vida, la supervivencia y el desarrollo; el respeto a sus opiniones, que implica la ciudadanía y la discriminación; y cualquier negación o exclusión por motivos de raza, pertenencia étnica, género o nacionalidad es inaceptable. De los 51 indicadores con que México se comprometió, para el año 2015, se logró un avance del 72.5\%. Fueron significativos el descenso de la mortalidad infantil, de 32.5 a 13 por 1000 nacidos vivos, y en menores de 5 años del 41 al 15.7\%. No obstante, en 2010, de 39,226,744 menores de 17 años, 10,428,007 vivían en 171,993 localidades de menos de 2500 habitantes, y 4,438,961 vivían con al menos un integrante de habla indígena, bajo acceso a la educación y la salud, y malnutrición. Los nuevos 17 objetivos y metas del desarrollo sostenible guiarán las decisiones que se adopten en los próximos 15 años. Once de ellos inciden en la niñez, con los que se esperaría logros cercanos a los de los países de la Organización para la Cooperación y el Desarrollo Económicos (OCDE) en educación, vivienda, seguridad y condiciones sanitarias.

Ghoran Therborn ${ }^{22}$, profesor sueco de sociología en la Universidad de Cambridge y autor del libro The Killingfield of inequality, cataloga la desigualdad en tres tipos:

- La vital, relacionada con las oportunidades desiguales ante la vida de los humanos. Puede evaluarse por tasas de mortalidad, esperanza de vida, años de vida libres de enfermedad, peso al nacer, desarrollo corporal, y encuestas de hambre y nutrición, entre otras. 
- La existencial, relacionada con la desigualdad personal de autonomía, dignidad, grados de libertad y de derecho al respeto y el desarrollo personal.

- La de recursos, que impide a los actores disponer de recursos similares para desenvolverse y que son la base de los discursos sobre desigualdad, en las que el dinero es lo principal, e incluye la desigualdad de oportunidades.

De tiempo atrás se reconoce que las inequidades dentro de una misma población hacen que ciertos grupos tengan menor acceso a los distintos servicios ofrecidos, ya sea de atención médica, educación o salud pública, entre otros. Por lo anterior, estos grupos nacen y viven a lo largo del ciclo de la vida en condiciones de desventaja, y no tienen igual acceso a la educación formal ni, en consecuencia, a trabajos seguros y con remuneración adecuada. En aspectos de salud, esta desventaja se refleja en la falta o la inadecuada atención en salud, lo que provoca que enfermen y mueran en mayor proporción que el resto de la población que se encuentra en condiciones más favorables.

Ciertamente, los factores sociales son elementos fundamentales de las causas de la mala salud y la enfermedad ${ }^{23}$. La fuerte relación del nivel socioeconómico, medido generalmente por el nivel educativo, el ingreso, la ocupación y el acceso a distintos recursos, con el estado de salud y bienestar de las personas está hoy en día bien establecida y es evidente a través del ciclo de vida. Paradójicamente, y contrario a lo que se pensaba hace algunas décadas, las inequidades sociales y en salud ocurren también en países desarrollados 0 «ricos», en los que, independientemente de contar con sistemas universales de educación y salud, o con estrategias para disminuir las desigualdades, estos contrastes existen y en ocasiones van en aumento ${ }^{24}$.

Una de las principales razones del aumento o la persistencia de las inequidades en salud es que, si bien un número significativo de problemas de salud pueden atribuirse a las condiciones socioeconómicas de una población, las políticas de salud se han enfocado principalmente en estrategias curativas, es decir, a tratar la enfermedad y no a tratar de atacar las "causas de las causas». De forma paralela, se ha mostrado que aquellos países que desarrollan políticas económicas y sociales redistributivas y de empleo formal tienen mayor éxito en mejorar la salud de la población y reducir las inequidades. En el ámbito local, estatal o de un país, las poblaciones con inequidades en salud, en el acceso a la educación formal, con inadecuada remuneración, y que nacen y viven en condiciones de desventaja, está demostrado que enferman y mueren en mayor proporción que las poblaciones que se encuentran en condiciones más favorables; inequidades que, por cierto, también se presentan en las grandes urbes. A ello se suman los efectos más desafortunados de una atención a la población de tipo curativo, en vez de preventivo.

Cuando el enfoque del análisis de los DSS va dirigido a los niños, teniendo como sustento sus derechos y su bienestar, deben considerarse cuatro principios básicos que en ellos se incluyen:

- El interés superior del niño.

- Su derecho a la vida, la supervivencia y el desarrollo.

- El respeto a sus opiniones, lo que implica la ciudadanía de niños, niñas y adolescentes.

- El principio de no discriminación, que significa que cualquier negación o exclusión por motivos de raza, pertenencia étnica, género o nacionalidad es inaceptable.

En el informe de la OMS del año $2009^{25}$ con respecto a la primera infancia se recomendó a los países, incluyendo México, acciones específicas para mejorar sus condiciones de vida. En las acciones por realizar se incluyeron garantizar la eficacia y la calidad; promover la participación social; fortalecer la función del sector salud; generar políticas y acciones sobre los DSS, y mantener la vigilancia del progreso de esas acciones mediante la medición y el análisis de las políticas y las acciones específicas.

Las evidencias actuales, sustentadas en investigaciones en salud y desarrollo, indican que los efectos adversos adquiridos durante la niñez se mantienen en la vida adulta, en los que influyen las deficiencias en el reconocimiento de los derechos de los niños y de los adolescentes; las fallas en el modelo médico que se utilice para atender todas las necesidades de los niños y adolescentes; el no utilizar modelos de atención primaria integral que favorezcan las acciones preventivas en lugar de las curativas; y el no promover modelos que incorporen a los niños como integrantes plenos dentro de un amplio contexto social, económico y político, entre otros.

\section{Los determinantes sociales de la salud y el bienestar de los niños en las zonas urbanas en el mundo}

La OMS calcula que uno de cada tres habitantes de las ciudades vive en tugurios inseguros, en viviendas hacinadas, antihigiénicas, con mayor contaminación, 
tráfico y delincuencia, con un alto costo de vida, deficiente cobertura de los servicios y competencia entre ellos por los recursos. De hecho, muchos habitantes urbanos viven cerca de escuelas y hospitales, pero tienen pocas posibilidades de usar estos servicios. En algunos casos, la pobreza urbana tiene condiciones tan malas o peores que las de los niños que viven en la pobreza rural, en términos del peso para la talla 0 de la mortalidad en menores de 5 años.

\section{Los determinantes sociales de la salud en los niños en América Latina y el Caribe}

En un estudio realizado en 2010 por CEPAL y UNICEF sobre la pobreza infantil en la Región de América Latina y el Caribe se encontró que uno de cada cinco niños de la región es extremadamente pobre, flagelo que afecta a más de 32 millones de ellos, y que uno de cada tres en situación de pobreza extrema se ve afectado en más de un derecho fundamental. Por otra parte, 2,3 millones tienen bajo peso para la edad y 8,8 millones están afectados por desnutrición crónica. Cuatro de cada 10 niños de zonas rurales se enfrentan a privaciones vinculadas a las inadecuadas condiciones de las viviendas en que habitan, lo que significa que el $9,4 \%$ (16,8 millones) no cuenta con un sistema de evacuación por alcantarillado. En total, los niños con privaciones, sean graves o moderadas, suman poco más de 46 millones en la región, dentro de los que los indígenas y los afrodescendientes presentan en mayor medida privaciones vinculadas al acceso a la educación y la información ${ }^{23}$.

\section{Algunas consideraciones de los determinantes sociales de la salud en México: infancias urbanas y rurales}

Según el Censo Nacional de Población del año 2010, del total de 39,226,744 niños de 0 a 17 años de edad, 10,428,007 vivían en 171,993 localidades de menos de 2500 habitantes, ubicadas en mayor proporción en Chiapas, Guerrero, Guanajuato, México, Oaxaca, Puebla, San Luis Potosí y Veracruz, y que de ellos, 4,438,961 vivían en un hogar con al menos un integrante de habla indígena.

En el Tercer Informe de la Convención sobre los Derechos del Niño de la ONU se señala a nuestro país su gran preocupación por el limitado ejercicio de los derechos de los niños indígenas, especialmente los trabajadores migrantes indígenas, en particular por el bajo acceso a la educación y la salud, por su tasa de malnutrición desproporcionadamente elevada y por la mortalidad materno-infantil.

\section{Los DSS y la población infantil con discapacidad}

En México, en el año 2006, según la información de la UNICEF ${ }^{26}$, mientras el promedio nacional de niños y niñas de entre 6 y 14 años que no asisten a la escuela es del $8.7 \%$, el promedio para la población infantil con discapacidad en ese rubro de edad se cuadriplica.

\section{Los DSS y el derecho a la identidad}

Las cifras nacionales muestran que, en el año 2004, el $25.3 \%$ de la población infantil no fue registrada antes de cumplir 1 año de edad, lo que disminuyó al $19.2 \%$ en el 2009 , brecha que, aunque se ha reducido, hace que se requiera avanzar sustantivamente a este respecto.

\section{Los DSS y la salud del adolescente}

La Dirección General de Epidemiología de la Secretaría de Salud informó de que, en el año 2010, la distribución de la población adolescente, de acuerdo con el grado de marginación, era del 17\% (3.6 millones de ellos) a pesar de los avances logrados en materia de desarrollo social y de salud.

En 2010 , el $78.5 \%$ de los adolescentes del país lograron aprobar la secundaria, el $15.4 \%$ no aprobó el nivel en curso y el $6.1 \%$ abandonó los estudios. Para el bachillerato, estas cifras estimaron que el $60 \%$ aprobó su grado, el $31.7 \%$ no lo aprobó y el $8.3 \%$ abandonó el curso.

Las principales causas de mortalidad en adolescentes de 10 a 19 años para el año 2010 fueron los accidentes, con una tasa de 39.4, los homicidios con 11.6 y los tumores malignos con 11.5. En el año 2009, un total de 11,360 niñas de 10 a 14 años registraron al menos un hijo vivo, y 204,547 de las de 15 a 17 años de edad.

\section{Los DSS y la vivienda}

En México, 14.6 millones de niños y niñas habitan en viviendas sin acceso al abastecimiento de agua; 13.4 millones no tienen conexiones a sistemas integrales de recolección y tratamiento final de residuos; viven sin electricidad 1.1 millones; 5.2 millones habitan en lugares con piso de tierra dentro de sus 


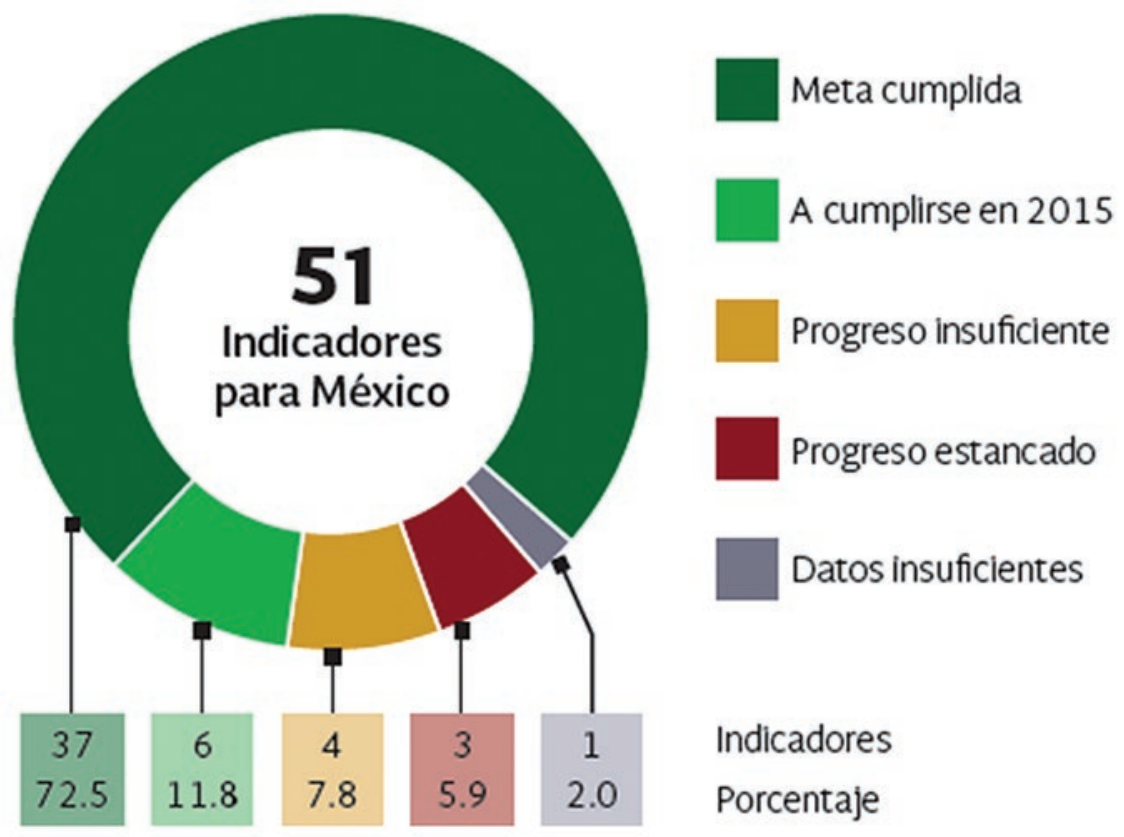

Figura 3. Cumplimiento de los indicadores de los Objetivos de Desarrollo del Milenio para 2015.

viviendas; y 18.6 millones viven en espacios en donde hay hacinamiento. El porcentaje de población infantil que habita en viviendas con hacinamiento se incrementó del $42.6 \%$ en el año 2000 al $49.2 \%$ en el año $2005^{27}$.

\section{Los DSS y la educación}

En el año 2010 hubo en México un total de 326,684 niños y niñas de 5 a 11 años de edad que no asistieron a la escuela. Respecto a la tasa neta de cobertura en educación, aunque de 2001 a 2011 se incrementó de 50.5 a 81.8 , es de hacer notar que la calidad es deficiente, como se encontró con respecto al elevado porcentaje de alumnos de sexto de primaria con logro insuficiente 0 básico en la prueba ENLACE28, comparando los resultados obtenidos en 2006 con los de 2011. Otro dato de las varias deficiencias es que 1,186,250 (9.1\%) de niños y niñas de 12 a 17 años, en el año 2010, no estudiaban ni trabajaban.

\section{Los DSS y la población infantil trabajadora}

Dos de cada ocho niños y niñas de entre 12 y 17 años forman parte de la población económicamente activa, con tasas superiores al $26 \%$ en los Estados de Campeche, Chiapas, Hidalgo, Jalisco, Nayarit, Sinaloa y Zacatecas.

\section{Los DSS y las leyes de protección en los Estados}

En el año 2006, 22 Estados de nuestro país ya contaban con leyes relacionadas con los derechos de niñas, niños y adolescentes, en las que se definen claramente su propósito o bien jurídicamente tutelado, y se considera a todos como sujetos plenos de derecho; sin embargo, el 18\% de los Estados aún no incorporaban en 2006 esta noción en su legislación ${ }^{29}$.

\section{Conclusiones}

De acuerdo con una lista oficial de indicadores publicada en 2005 y revisada en 2009, el Gobierno de México comprometió sus esfuerzos en torno a 51 indicadores de los ODM, 41 de la lista oficial de las Naciones Unidas y 10 reformulados para México ${ }^{8}$. La evaluación de los resultados es positiva: se han alcanzado las metas correspondientes a 37 indicadores (72.5\%) y se espera cumplir con seis más $(11.8 \%)$ antes de finalizar 2015. En cuatro indicadores (7.8\%) se observan avances, pero han sido insuficientes para cumplir con las metas previstas; en tres (5.9\%) prevalece una situación de estancamiento; y con respecto a uno, debido a la naturaleza propia del indicador, la información es insuficiente para derivar mediciones concluyentes (Fig. 3). 
La aplicación de los nuevos objetivos y metas del desarrollo sostenible entró en vigor a partir del mes de enero de 2016 y guiarán las decisiones que se adopten durante los próximos 15 años. De los 17 ODM con que México se comprometió en esta nueva etapa, seis tienen especial mención en relación con la infancia. Lo anterior, de manera independiente a los 11 objetivos restantes que, de una $u$ otra manera, también inciden en la niñe $z^{30}$.
Para lograr en un plazo de 15 años índices iguales o cercanos a los de los países de mayor desarrollo, integrantes de la OCDE, es necesario incidir en las deficiencias en educación, vivienda, seguridad y condiciones sanitarias de las localidades, entre otras, con metas específicas por lograr, las cuales sean medidas en períodos trianuales 0 sexenales.

\section{La transición de los Objetivos del Milenio a los Objetivos de Desarrollo Sostenible: El impacto sobre la equidad de género. La fecundidad adolescente como estudio de caso}

Los DSS son la "causa de las causas» de las brechas en salud que experimentan las personas, las comunidades y los países. Para reducir estas brechas surgen los ODS, compromisos internacionales asumidos en términos de desarrollo, salud, acceso a educación, al trabajo y a tecnologías, en un marco de derechos, de sostenibilidad y de igualdad para todos. Los ODS 3, 4 y 7 son particularmente claves para lograr el bienestar de niñas, adolescentes y mujeres.

Ya los ODM comprometieron a los países a avanzar en estos temas, pero los logros fueron insuficientes y profundamente desiguales. Como ejemplo, analizaremos la fecundidad adolescente en México, que aumentó a niveles de hace dos décadas. El embarazo temprano es causa y consecuencia de la pobreza, del bajo nivel educativo, de la falta y desigualdad de acceso al desarrollo y a servicios de salud, de la violencia y la discriminación, de las normas sociales y los marcos legales que limitan el empoderamiento de las mujeres. Se necesitan políticas integrales y focalizadas en educación, salud y desarrollo de niñas, adolescentes y mujeres, para lograr el bienestar de ellas, de sus hijas/ os, de sus familias y de sus comunidades.

\section{Introducción}

Lograr la salud y el bienestar de las personas, comunidades y países es un proceso que requiere, cada vez más, integrarse a la promoción y al acceso a la educación, al desarrollo, a una vida sin violencia, a un trabajo digno, a tecnologías de la comunicación, a un ambiente sano y sostenible, en un marco de respeto a los derechos humanos y de igualdad para todas y todos. La pobre salud materna, sexual y reproductiva de la población adolescente en México se analiza aquí como un marcador claro de inequidades y de violación de los derechos humanos fundamentales a la vida, la salud y el libre desarrollo de la persona.

\section{Los determinantes sociales de la salud}

Desde hace aproximadamente una década y media se ha ido definiendo un nuevo marco conceptual de la salud, que se enfoca a aquellas condiciones, externas a la persona y a las patologías individuales, pero que impactan sobre ellas de manera significativa y diferencial. Estas condiciones, y los factores sociales que influencian la salud y los sistemas de salud, se han denominado "determinantes sociales de la salud" y se consideran la "causa de las causas" de las inequidades en salud ${ }^{31}$. Se incluyen aquí los estilos de vida individuales y grupales, la presencia de redes sociales y comunitarias, las condiciones en las cuales las personas viven y trabajan, su pertenencia étnica, su acceso a la educación formal, su estatus socioeconómico, su acceso a los alimentos, al agua y al saneamiento básico ambiental, y por supuesto la disponibilidad, la accesibilidad y la calidad de los servicios de salud. Todas estas condiciones impactan de manera diferente en el proceso de salud-enfermedad de las personas, las familias, las comunidades, los pueblos y las naciones. Se asume que, para mejorar la salud y prevenir 
la enfermedad, es tan importante incidir en estas condiciones como impactar en las patologías específicas e individuales.

\section{La Agenda 2030 y los Objetivos de Desarrollo Sostenibles ante la salud materna, sexual y reproductiva}

En esta perspectiva se sitúan la Agenda 2030 para el Desarrollo Sostenible y sus 17 ODS. Estos nuevos compromisos fueron asumidos por los Estados miembros de la ONU en la Cumbre para el Desarrollo Sostenible, en septiembre de $2015^{32}$. Los ODS comprometen a la comunidad internacional a poner fin a la pobreza, a luchar contra las brechas de desigualdad y la injusticia, y a hacer frente al cambio climático para alcanzar la salud, la educación y el desarrollo en un marco de sostenibilidad, de derechos y de igualdad entre países y al interior de los países. En especial, del conjunto de los 17 ODS (todos ellos interconectados e interdependientes) señalaremos tres como los más relevantes para conseguir logros en educación, salud y bienestar de las mujeres, niñas y adolescentes, para mejorar la salud materna, sexual y reproductiva, para eliminar la violencia y alcanzar la igualdad de género. Estos son:

- ODS 3: «Salud y bienestar: garantizar una vida sana y promover el bienestar para todos en todas las edades». Se relaciona directamente con la salud sexual, reproductiva, materna y neonatal, en particular a través de las metas 3.1 (reducir la tasa mundial de mortalidad materna a menos de 70 por cada 100.000 nacidos vivos) y 3.7 (garantizar el acceso universal a servicios de salud sexual y reproductiva, incluidos la planificación familiar, información y educación, y la integración de la salud reproductiva en las estrategias y los programas nacionales). Para esto, toma en cuenta la necesidad de una cobertura y acceso universal en salud, para todas las personas.

- ODS 4: «Educación de calidad: garantizar una educación inclusiva, equitativa y de calidad, y promover oportunidades de aprendizaje durante toda la vida para todos". Identifica la educación formal en las primeras décadas de la vida, pero también los procesos de aprendizajes permanentes durante toda la vida, como uno de los mecanismos clave para lograr el desarrollo, acceder a un trabajo decente y reducir las inequidades. En particular, pretende reducir las inequidades entre los sexos a través de sus metas 4.5 (eliminar las disparidades de género en la educación y garantizar el acceso igualitario de las personas vulnerables ... a todos los niveles de la enseñanza y la formación profesional), 4.7 (garantizar que todos los estudiantes adquieran los conocimientos teóricos y prácticos necesarios para promover el desarrollo sostenible, en particular mediante la educación para el desarroIlo sostenible y la adopción de estilos de vida sostenibles, los derechos humanos, la igualdad entre los géneros, la promoción de una cultura de paz y no violencia ... entre otros medios) y 4.8 (construir y adecuar instalaciones escolares que respondan a las necesidades de los niños y las personas discapacitadas y tengan en cuenta las cuestiones de género, y que ofrezcan entornos de aprendizaje seguros, no violentos, inclusivos y eficaces para todos).

- ODS 5: «lgualdad de género: lograr la igualdad entre los géneros, erradicar la violencia de género y promover el empoderamiento de todas las mujeres y niñas, a través en especial de sus metas 5.2 (eliminar todas las formas de violencia contra todas las mujeres y las niñas en los ámbitos público y privado, incluidas la trata y la explotación sexual y otros tipos de explotación) y 5.6 (garantizar el acceso universal a la salud sexual y reproductiva, y los derechos reproductivos), y en general reducir y eliminar la discriminación y las múltiples violaciones a sus derechos políticos, económicos, sociales y culturales.

La Agenda 2030 y los ODS se vinculan por supuesto con el resto de los procesos y compromisos internacionales, en particular con aquellos mecanismos que dan seguimiento y continuidad a los Planes de Acción de las Conferencias Internacionales de Población, en El Cairo en 1994, y de la Mujer, en Pekín en 1995, en los ámbitos regional e internacional. Como se afirma, en especial, en los documentos de la región Latinoamericana y del Caribe: «El desarrollo es indisociable de la erradicación de la pobreza y la ruptura de los círculos de exclusión y desigualdad, de la centralidad de los derechos humanos, y de la sostenibilidad, que supone la satisfacción de las necesidades de la generación presente sin comprometer la capacidad de las generaciones futuras de satisfacer sus propias necesidades» ${ }^{33}$. 


\section{Logros y retos de México ante la salud materna, sexual y reproductiva}

Vamos a analizar brevemente los avances y los retos que México ha enfrentado ante las metas comprometidas en los $\mathrm{ODM}^{34}$, y que presenta ahora frente a los nuevos ODS, en particular en lo que concierne a la salud materna, sexual y reproductiva de las mujeres, y más aún de sus niñas y adolescentes. Es cierto que nuestro país ha logrado avances significativos en los indicadores comprometidos para $2015^{35}$. De acuerdo con el ODM 5A (reducir, entre 1990 y 2015, la mortalidad materna en tres cuartas partes), reportó un aumento de 20 puntos porcentuales en la cobertura de partos por personal capacitado, de 76.7 en 1990 a 96.3 en 2014 (último dato disponible en el informe oficial). En el ODM 5B (lograr, para el año 2015, el acceso universal a la salud reproductiva), reportó un aumento en la prevalencia de anticonceptivos en mujeres de 63.1 en 1992 a 72.3 en 2014, y una reducción en la necesidad insatisfecha de 25 en 1987 a apenas 5.0 en $2014^{35}$.

Sin embargo, el país ha quedado lejos de cumplir la Meta $5 \mathrm{~A}$ (reducción de la razón de mortalidad materna') a 22.2 por 100,000 nacidos vivos para 2015, reportando oficialmente 38.2 en 2013 , comparada con una basal de 88.7 en 1990. Finalmente, México no ha cumplido con el compromiso de reducir la tasa de fecundidad adolescente"; si bien el Informe oficial de Avance $2015^{35}$ reporta que esta disminuyó de 76.8 en el año 1990 a 65.7 estimada para 2014, la realidad de las encuestas posteriores, en particular de la Encuesta Nacional de la Dinámica Demográfica (ENADID 2014), revela inesperadamente que la tasa de fecundidad adolescente no solo no disminuyó, sino que repuntó nuevamente a 77 por 1000 en los años recientes ${ }^{36}$. Adicionalmente, en términos de salud materna, sexual y reproductiva de niñas, adolescentes y mujeres, los logros nacionales han sido profundamente desiguales y marcados por los determinantes sociales que siguen profundizando las brechas.

\section{Las transiciones de la adolescencia}

Resumimos aquí brevemente los indicadores de las diversas transiciones que experimenta la población adolescente en México, desde el inicio de la vida

I Número de defunciones por causas maternas por cada 100,000 nacidos vivos.

II Número de adolescentes de 15 a 19 años con por lo menos un hijo nacido vivo por cada 1000 adolescentes en la población. sexual activa, la edad de la primera unión y la edad del primer embarazo, de acuerdo con los datos que las varias rondas de las principales encuestas (la Encuesta Nacional de Salud y Nutrición [ENSANUT] y la Encuesta Nacional de la Dinámica Demográfica [ENADID]) nos proporcionan oficialmente. Es claro, sin embargo, que el concepto mismo de «transiciones» como una secuencia ordenada y lógica de eventos ha ido cambiando de manera significativa entre las generaciones más recientes. En las generaciones de nuestras abuelas era normal que la unión o matrimonio fuera temprano (p. ej., a los 15-17 años), que sucediera poco después de la menarquia (es decir, del inicio de la función reproductiva en esas épocas), que después y dentro de esta primera unión se iniciara sexualmente la pareja (al menos la mujer), y que poco después se concibiera y naciera su primer/a hijo/a. En esas circunstancias, los mandatos culturales y morales de la «abstinencia hasta el matrimonio" implicaban solo muy pocos años de observancia en la mayoría de la población.

En la actualidad, solo dos o tres generaciones más tarde, han cambiado la secuencia, los tiempos y las aspiraciones de la población adolescente, por lo menos en ciertos niveles educativos y socioeconómicos. La menarquia es más precoz y el inicio de la vida sexual activa es cada vez más temprano, pero no se presenta necesariamente dentro de la primera unión o del matrimonio; de hecho, puede haber un desfase de varios años, hasta de más de una década, entre el inicio de la vida sexual activa y la primera unión, que se intenta retrasar hasta cumplir con nuevas metas y nuevas aspiraciones educativas y de realización profesional, en ambos sexos. Este desfase creciente genera profundos conflictos en el manejo de la sexualidad y una incapacidad objetiva de cumplir con el mandato de la abstinencia. La dificultad de conciliar los nuevos roles aspiracionales de nuestros adolescentes con modelos culturales y morales inamovibles, sin una educación sexual a la altura de la realidad y de las necesidades actuales, y con un acceso restringidos a servicios y métodos anticonceptivos, resulta con frecuencia en deserción escolar, embarazos tempranos, concepciones afuera y antes de la unión, infecciones de transmisión sexual y alteraciones de todo el proyecto de vida.

\section{Edad de las transiciones de la adolescencia}

Si analizamos los hallazgos de las encuestas más recientes, en particular de la ENADID $2014^{36}$, pero 
con anterioridad también de la ENSANUT 2012 27 II',podemos observar que la edad mediana de las principales transiciones de la adolescencia presenta un importante adelanto en los últimos años. Sin embargo, esta tendencia está modulada de manera muy importante por algunos determinantes sociales de marginación, como la pertenencia étnica a población indígena, la residencia rural-urbana y, en especial, el nivel de educación formal alcanzado por las adolescentes y jóvenes.

De acuerdo con los más recientes reportes oficiales de la ENADID 2014 ${ }^{38}$, la edad mediana de inicio de la vida sexual activa en las mujeres de las cohortes más jóvenes (de 25 a 34 años) se ha adelantado un año en comparación con el resto de las mujeres en edad reproductiva (de 35 a 49 años), y se sitúa en la actualidad en los 17 años y 7 meses. En 28 de las 32 entidades federativas se confirma el adelanto, mientras solo cuatro de ellas experimentan una demora en este indicador. Sin embargo, si se analiza según la escolaridad, la edad mediana oscila entre un mínimo de 15.9 años en las mujeres con primaria incompleta o menos y un máximo de 17.9 en aquellas con educación secundaria o más. La edad mediana en el momento de la primera unión también experimenta un anticipo: ha pasado de 19.7 años en las cohortes de mujeres mayores (35-49 años) a 18.8 en las mujeres más jóvenes (25-34 años). Nuevamente, la escolaridad es la que impacta más significativamente, con hasta 3 años de diferencia: mientras que las mujeres sin escolaridad o con primaria incompleta se unen a los 16.6 años, aquellas con secundaria y más lo hacen a los 19.6 años ${ }^{38}$.

Finalmente, la edad mediana al primer hijo nacido vivo, la última transición sexual y reproductiva de la adolescencia, se ha adelantado 1 año entre las cohortes de mujeres más jóvenes (19.5 vs. 20.6), pero difiere profundamente de acuerdo con los niveles de escolaridad alcanzados: 17.5 vs. 20 años $^{38}$. Vale la pena señalar que, al analizar la influencia de la escolaridad en todos estos indicadores, el mayor salto diferencial se observa con secundaria completa o más; haber alcanzado solo la primaria completa no parece ya otorgar el efecto supuestamente protector que se podía observar hace algunas décadas.

III El INSP levantó posteriormente la ENSANUT 2016, cuyos hallazgos no se incluyen en este artículo.

\section{Uso de anticonceptivos en población adolescente}

En sentido inverso a estos indicadores, es importante señalar una tendencia marcadamente positiva que caracteriza los comportamientos sexuales y reproductivos de nuestra población adolescente en años recientes: el aumento en el uso de métodos anticonceptivos, medidos durante la primera y la última relación sexual.

Ya en la ENSANUT 2012 se había identificado un aumento significativo en toda la nación en el uso de anticonceptivos durante la iniciación sexual, tanto entre adolescentes varones como entre mujeres. Adicionalmente, se destacaba la reducción de las brechas geográficas entre regiones más y menos marginadas; por ejemplo, el uso del condón se había duplicado entre 2006 y 2012 (del 22 al 44\%) entre adolescentes de la región sur del país, casi alcanzando el promedio (48\%) reportado en todo el territorio nacional ${ }^{39}$. De acuerdo con la ENADID 2014, el uso de anticonceptivos en el momento de inicio de la vida sexual activa pasa del 38.5 al $54.5 \%$ en las mujeres adolescentes, comparado con la ENADID 2009. La figura 4 señala claramente las mejorías generacionales y nos muestra que las adolescentes y las jóvenes de hoy se "comportan" mucho mejor que sus madres y abuelas; sin embargo, también evidencia lo que falta por hacer: poco menos de la mitad de las adolescentes inician su vida sexual sin protección ${ }^{38}$. Adicionalmente, la brecha representada por la deprivación educativa es enorme y se mantiene en el tiempo; este indicador es de apenas el $4.1 \%$ en las mujeres sin escolaridad o con primaria incompleta, y se multiplica diez veces, para llegar al $41.7 \%$, en aquellas con secundaria incompleta o más. Vale la pena señalar, en todo caso, que ambos indicadores aumentan significativamente en comparación con el año 2009, cuando eran del 2.2 y el $26 \%$, respectivamente ${ }^{38}$.

El indicador del uso de anticonceptivos en eventos puntuales es por supuesto insuficiente para caracterizar y entender las conductas anticonceptivas de adolescentes, hombres y mujeres. En particular, si el objetivo es retrasar la edad del primer embarazo a término y alargar el intervalo intergenésico, hay que analizar con más profundidad el tipo de métodos utilizados, la continuidad y la secuencia temporal del uso, en particular antes, y por supuesto después, del primer evento reproductivo. Al respecto del tipo de anticonceptivos utilizados, la enorme mayoría de las 


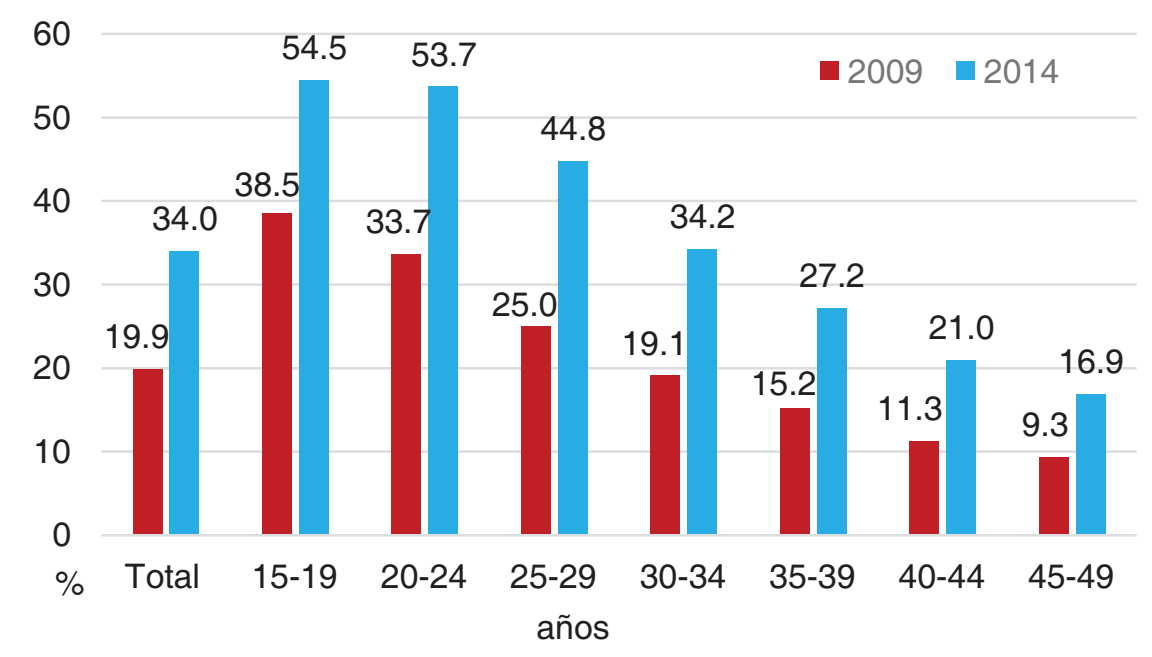

Figura 4. Uso de anticonceptivos (\%) en la primera relación sexual por grupo de edad, México 2009-2014. Fuente: elaboración propia, a partir de ENADID 2009-2014, ENADID 2014'.

adolescentes, al momento de su última relación sexual, declaran haber utilizado el condón $(48 \%)$, los hormonales $(6 \%)$ y la pastilla anticonceptiva de emergencia (4\%); apenas el $7 \%$ de ellas relata el uso del dispositivo intrauterino, y poco menos del $1 \%$ del implante subdérmico ${ }^{39}$. Solo estos dos últimos métodos pertenecen a la categoría de los anticonceptivos reversibles de acción prolongada (LARC, Long Acting Reversible Contraceptives). La característica de los LARC es la elevada efectividad ( $<1-2 \%$ de fallas), que además no es dependiente del usuario, es decir, no está determinada por la adherencia, la motivación, el recordatorio o, en una palabra, el uso perfecto y constante por parte de la usuaria, lo que condiciona las fallas en caso de métodos como el condón o las pastillas. Sin embargo, los LARC, a pesar de estas indiscutibles ventajas, presentan una gran desventaja: son dependientes de un proveedor, es decir, deben ser indicados e insertados por un profesional de la salud. Sabemos que existen todavía importantes barreras para acceder a los servicios de salud, y entre los profesionales de la salud para indicar el uso de los LARC en menores de edad. Se perciben supuestas barreras legales, relacionadas con el consentimiento informado, la autorización de los padres, etc., pero también existen mitos y barreras técnicas, sobre todo en relación con su uso en adolescentes nulíparas (desconocimiento de los criterios internacionales y nacionales de elegibilidad). Evidencias en este sentido pueden observarse en el acceso diferencial a los LARC que tienen las adolescentes, antes o después de un primer embarazo a término, en las diferentes instituciones del sector salud nacional ${ }^{40}$. Es posible, por lo tanto, que la distribución actual de los anticonceptivos utilizados por la población adolescente en México refleje no tanto las barreras, los mitos y los desconocimientos sobre ellos mismos, sino también las barreras y los sesgos radicados en los proveedores de los servicios de salud. En pocas palabras, las y los adolescentes han mejorados sus intenciones y sus conductas de protección, pero lo hacen con aquellos métodos anticonceptivos que pueden conseguir directamente (en farmacias) y que no requieren pasar los «filtros» de accesibilidad -en todos sentidos de la palabra- de los servicios. Para superar estas barreras se requieren, por supuesto, estrategias diferentes, aun cuando complementarias, para las dos poblaciones: usuarias/os y personal de salud.

\section{La fecundidad temprana: un reto creciente para México}

Las importantes mejoras en algunos indicadores de cobertura anticonceptivos van en contrasentido con el aumento en la fecundidad adolescente que las encuestas reportan. ¿Cómo podemos interpretar estos fenómenos aparentemente contradictorios? ¿Dónde radican los retos? El aumento de la fecundidad adolescente, y sobre todo en niñas menores de 15 años, constituye un ejemplo muy simbólico y complejo de los retos inacabados en salud, igualdad y derechos humanos en esta población. De acuerdo con las diferentes rondas de la ENADID ${ }^{36,38}$, la tasa de fecundidad adolescente, que había disminuido entre 1997 y 2009, repuntó a 77 en 2014 (Fig. 5). 


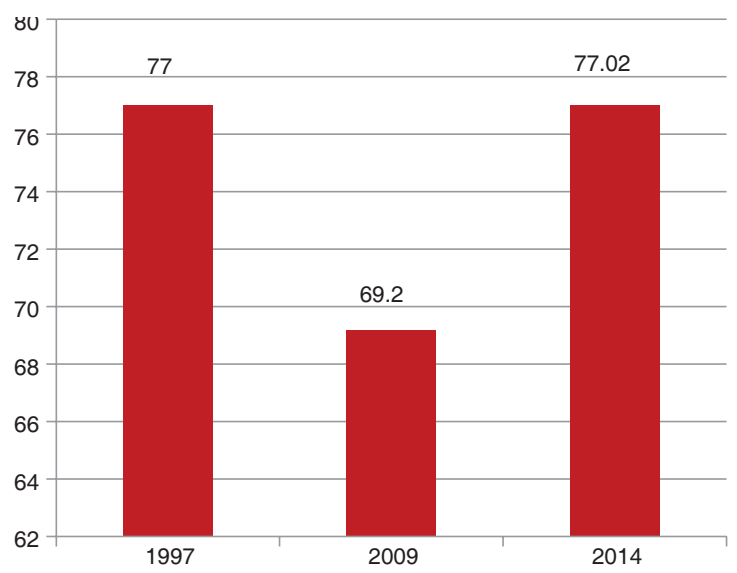

Figura 5. Tasa de fecundidad adolescente (adolescentes con por lo menos un hijo nacido vivo por 1000 adolescentes) en México, 19972014. Fuente: ENADID $2014^{6}$.

\section{La fecundidad muy temprana: un fenómeno poco estudiado}

Las encuestas tradicionales de fecundidad y salud en México, pero también en el resto del mundo, se aplican a adolescentes unidas de 15 años o más. Poco se sabe, por ende, de las menores de 15 años, las más vulnerables y las más invisibles. Una nueva fuente nos ayuda, sin embargo, a generar información sobre el fenómeno. Se trata del Sistema de Información sobre Nacimientos (SINAC), vigente desde 2008, que se fundamenta en la nueva obligación de emitir un certificado en todo nacimiento que sea asistido en cualquier unidad médica ${ }^{41}$.
A pesar de presentar problemas de subregistro (no incluye los nacimientos afuera de las unidades médicas) y de datos incompletos, particularmente en los primeros 2 años de su implementación, el sistema ha ido mejorando en cuando a cobertura y oportunidad del registro, y permite analizar varias características, sociodemográficas y biomédicas, asociadas al embarazo y al nacimiento. Ipas México ha analizado esta fuente de información oficial, identificando algunos hallazgos novedosos que confirman a escala nacional lo que otras investigaciones han señalado en contextos internacionales. Con la finalidad específica de investigar la fecundidad en la adolescencia temprana, hemos enfocado el análisis del SINAC 2008-2011 a los siguientes subgrupos de madres adolescentes: 10-14 años. 15-17 años y 18-19 años; en comparación con madres de 20-24 años como grupo control. Los resultados nos indican que, en el periodo analizado, de un total de 8,263,020 nacimientos registrados a esa fecha en el SINAC, el $19.6 \%$ fueron en adolescentes de 10-19 años, y de ellos el 0.7\% fueron en madres de 10-14 años (con un máximo del 1.3\% en Campeche y un mínimo del $0.5 \%$ en Aguascalientes, Nuevo León y Querétaro) ${ }^{42}$. Es importante señalar que la proporción de nacimientos tempranos se distribuye en las entidades federativas de acuerdo con criterios relativamente insospechados: si bien es mayor en los estados del sur/sureste, con menor índice de desarroIlo, también hay picos en regiones del norte y del centro del país, donde las causas del fenómeno parecen ser distintas de las comúnmente esperadas (Fig. 6).

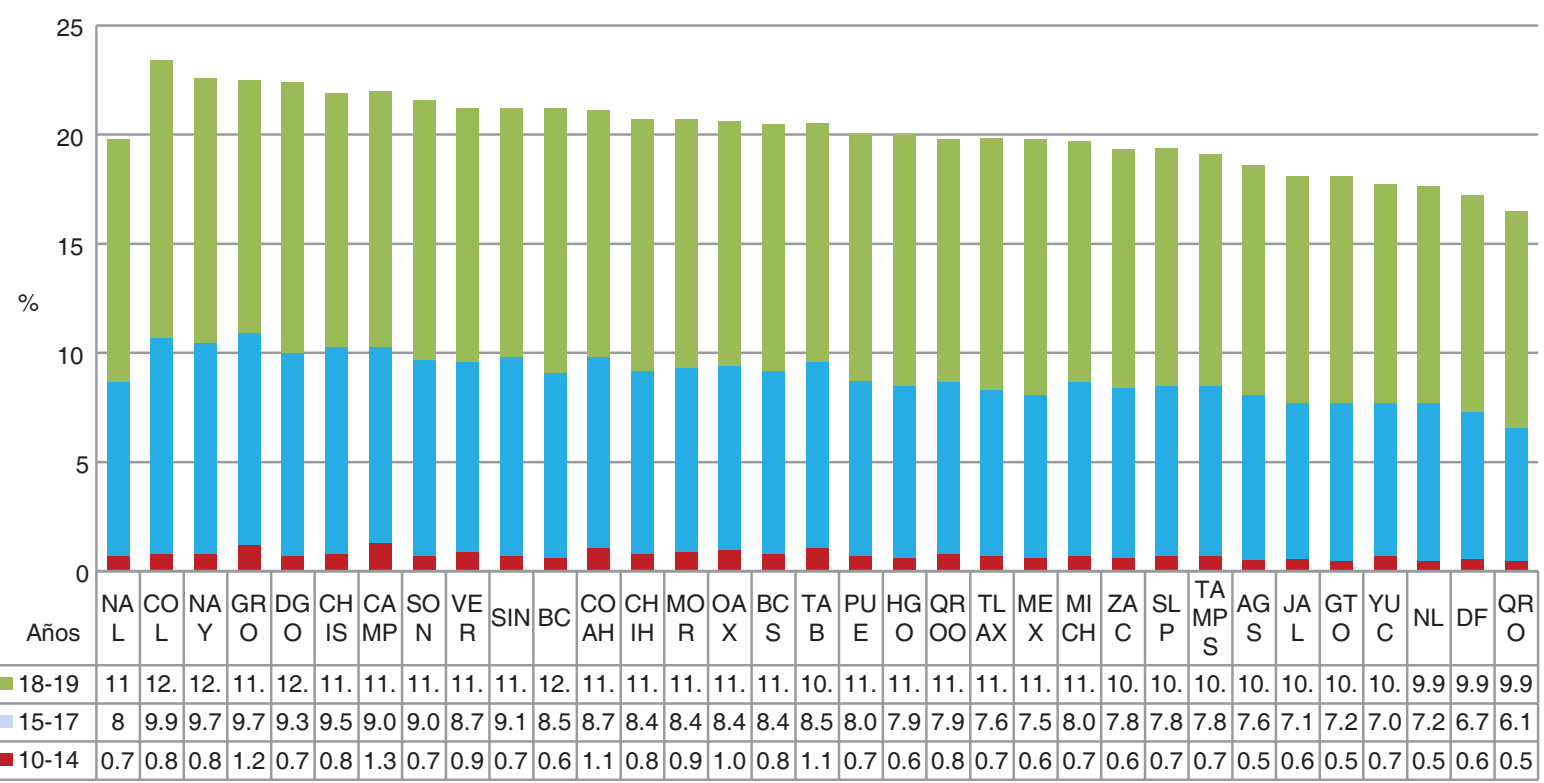

Figura 6. Proporción de nacimientos por grupo de edad de la madre y por Estado de registro. SINAC, 2008-2011. Fuente: análisis propio a partir de la base de datos de SINAC ${ }^{12}$ 
Tabla 1. Nacimientos en adolescentes. SINAC, 2014 y 2015. Fuente: elaboración propia a partir de la base de datos de SINAC ${ }^{12}$

\begin{tabular}{lcc}
\hline Edad (años) & $\mathbf{2 0 1 4}(\mathbf{N})$ & $\mathbf{2 0 1 5}(\mathbf{N})$ \\
\hline$<10$ & 1 & 7 \\
$10-14$ & 6,385 & 12,267 \\
$15-19$ & 378,673 & 404,180 \\
Total $<20$ & 385,059 & 416,454 \\
\hline
\end{tabular}

Adicionalmente, las adolescentes muy jóvenes presentaron mayor probabilidad de no tener educación alguna o un nivel de educación bajo, de no tener una ocupación, de ser solteras y de no tener derechohabiencia, en comparación con el grupo control de 20-24 años y con el resto de las madres adolescentes. En cuanto a los controles prenatales, estos fueron tanto más tardíos cuanto más temprana la edad materna, con diferencias significativas en cada subgrupo de edad (y entre todas las adolescentes) respecto al grupo control. Finalmente, el grupo de 10-14 años presentó mayores tasas de hijos con bajo $(1500-2500 \mathrm{~g})$ y muy bajo $(<1500 \mathrm{~g})$ peso al nacer, así como mayores tasas de partos pretérmino $(<$ 37 semanas de gestación) y muy pretérmino (32-37 semanas de gestación), comparadas con el resto de las adolescentes y con las mujeres de 20-24 años. En general, estas tasas disminuyen de manera consistente a medida que la edad materna aumenta, y siempre son mayores en el grupo de mujeres de 10-14 años ${ }^{43}$. En resumen, los hallazgos evidencian la vulnerabilidad social, así como la vulnerabilidad biomédica, de las niñas y adolescentes que se vuelven prematuramente madres en nuestro país. Nuestros análisis del mismo SINAC en años posteriores confirman, por un lado, la incidencia creciente del fenómeno, sobre todo de embarazos muy tempranos (Tabla 1), y por el otro ratifican el impacto que la edad materna tiene en la premadurez y el bajo peso al nacer de los/las hijos/as de niñas y adolescentes (datos no publicados).

\section{¿Quiénes son los padres? La violencia como determinante de la fecundidad temprana}

Demasiado poco se sabe de quiénes son los hombres que engendran hijos con niñas y adolescentes, ya que la mayoría de las encuestas, nacionales e internacionales, no recaban la información necesaria al respeto. Tampoco el SINAC recoge en su registro la información relativa a la edad del padre, o supuesto tal. Si bien indudablemente esta informacion tendría un fuerte sesgo por ser autorreportada, es también muy cierto que constituiría un elemento esencial para enteder más en profundidad el fenómeno del embarazo adolescente, sobre todo en las menores de 15 años. Nuestra organización ha buscado un indicador proxi de la paternidad en las bases de datos de la ENSANUT 2012. Esta encuesta pregunta la edad de la primera relación y la edad de la primera pareja con quien las adolescentes más jóvenes iniciaron su vida sexual. Los hallazgos preliminares que mostramos a continuación se refieren exclusivamente a dos grupos de edad, las niñas $<12$ años y las niñas de 12-14 años, presentando la distribución de la edad de su primer pareja masculina. Solo el $5 \%$ en el grupo de niñas $<12$ años y el 11\% de las niñas de 12-14 años tenían parejas masculinas de entre 10 y 14 años, es decir, eran coetaneos; el resto eran adolescentes mayores 0 adultos (Fig. 7). Ante estas diferencias de edad

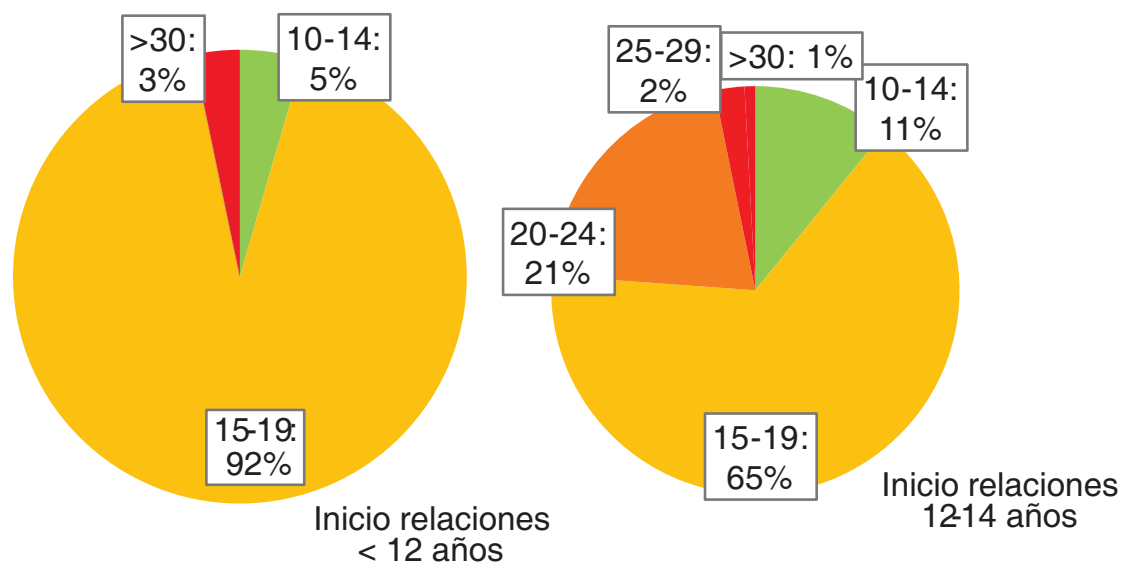

Figura 7. Distribución porcentual de la edad (en años) de la pareja masculina cuando la adolescente inició las relaciones sexuales. Fuente: análisis propio a partir de la base de datos de ENSANUT $2012^{7}$. 
y de «poder», poco sirven las intervenciones miradas a promover la educación sexual y adoptar métodos anticonceptivos; lo que se requiere son leyes y políticas públicas que, en la teoría, pero sobre todo en la práctica de la impartición de justicia, sean capaces de protegerá las niñas y adolescentes de la violencia. Cabe señalar en particular que, de acuerdo con el marco jurídico de nuestro país, una persona «menor de 12 y hasta 15 años» no puede otorgar el consentimiento a una relación sexual con una persona adulta; tales relaciones se consideran por lo tanto violaciones, aun cuando no haya obrado violencia física ${ }^{44}$. En consecuencia, los embarazos que resulten pueden ser interrumpidos en un marco legal, si así lo solicita la víctima, inclusive sin que medie una denuncia o una autorización del ramo judicial ${ }^{45}$.

La literatura internacional ya había señalado que el embarazo en niñas y adolescentes es con frecuencia el resultado de la violencia sexual, y que cuanto más joven es la madre adolescente, más probable es la violencia y mayor es el diferencial de edad con el pa$\mathrm{dre}^{46}$. Nuestros hallazgos sugieren fuertemente que también en nuestro país una de las causas frecuentes del embarazo temprano es la violencia, familiar, sexual y de género, en todas sus formas, desde la violación intrafamiliar, el matrimonio y la unión infantil, la «venta» de hijas menores, la violencia criminal de pandillas y de la delincuencia organizada, y la trata de menores ${ }^{47}$.

\section{El Sistema de Salud de México y la transición de los Objetivos del Milenio a los Objetivos de Desarrollo Sostenible}

En 2015 concluye la etapa de los ODM y da inicio la nueva política mundial de Transformar nuestro mundo: la agenda 2030 para el desarrollo Sostenible. México, como país miembro de la ONU, se compromete a cumplir con los objetivos trazados y presentar periódicamente informes sobre los avances alcanzados. En materia de salud, los compromisos abarcan una agenda ambiciosa, con metas bien definidas, que concluye en 2030. Para cumplir con los compromisos se requieren cambios y adecuaciones del Sistema de Salud de México y, como señala el marco conceptual de los ODS, un nuevo conocimiento alrededor de la gobernanza y la gerencia de las instituciones.

El presente documento hace un breve recorrido en el transitar de los ODM a los ODS. Describe las necesidades de salud cambiantes de la población mexicana, caracteriza el sistema de salud del país y presenta los retos a los que se enfrenta para sincronizarse con las necesidades de salud del siglo XXI y rendir cuentas satisfactorias en el plazo convenido.

\section{Introducción}

En septiembre de 2015, en la sede de la ONU en Nueva York, concluye la primera fase de la política mundial de desarrollo que se inició con el siglo XXI y arranca un nuevo periodo sobre el desarrollo sostenible de ámbito global que abarca de 2015 a 2030. El propósito central de la primera etapa fue «reducir a la mitad el porcentaje de habitantes del planeta cuyos ingresos sean inferiores a un dólar por día y el de las personas que padezcan hambre; igualmente, para esa misma fecha, reducir a la mitad el porcentaje de personas que carezcan de acceso a agua potable 0 que no puedan costearla...» ${ }^{48}$. En ese entonces, el Secretario General de la ONU partió de un marco de referencia en el que colocaba al ser humano en el centro del desarrollo, y formuló, en un mapa de ruta publicado en 2001, los ocho ODM ${ }^{49}$. Esta fue la guía mediante la cual se dio seguimiento a los esfuerzos para liberar a hombres, mujeres, niñas y niños, de las condiciones abyectas y deshumanizadoras de la pobreza extrema. Todo el esfuerzo se hizo bajo el empeño de hacer realidad para todos ellos el derecho al desarrollo.

En esos días, con un balance muy positivo para el periodo de 1990 a 2015, se informó a la Asamblea de que la tasa de pobreza extrema en el mundo se había reducido del 47 al $14 \%$, y el número de personas que vivían en pobreza extrema había disminuido de 1900 millones a 836 millones. En otras palabras, más de la mitad de lo que se había planeado. 
Los resultados en otras metas fueron muy alentadores. La tasa mundial de mortalidad de niños menores de 5 años disminuyó más de la mitad, reduciéndose de 90 a 43 muertes por cada 1000 nacidos vivos entre 1990 y 2015 . Más del $71 \%$ de los nacimientos en todo el mundo fueron atendidos en 2014 por personal de salud capacitado, lo que significa un aumento desde el $59 \%$ en 1990. La prevalencia de anticonceptivos entre las mujeres de 15 a 49 años, casadas o que viven en pareja, se incrementó del $55 \%$ en todo el mundo en 1990 al $64 \%$ en 2015. Sin embargo, el resultado más alentador fue que la asistencia oficial para el desarrollo por parte de los países desarrollados aumentó un $66 \%$ en términos reales entre los años 2000 y 2014, alcanzando 135,200 millones de dólares ${ }^{50}$. La solidaridad internacional requerida para el desarrollo empezaba a cobrar vida.

Sin embargo, no todas fueron buenas noticias. La desigualdad de género no se aminoró; las brechas entre pobres y ricos, y entre rural y urbano, no solo no disminuyeron, sino que se exacerbaron. Quedaron países rezagados con lo programado para mortalidad materna y mortalidad infantil. Pero lo más lamentable es el nivel de deterioro en que se encontraba el medio ambiente. De acuerdo con el reporte del Instituto de la Resiliencia, ubicado en Estocolmo (Suecia) ${ }^{51}$, tres de los nueve límites planetarios que ellos identifican han sido rebasados, a saber, el cambio climático (huella de carbono), la pérdida de biodiversidad y los cambios en el ciclo global del nitrógeno. Lo grave de esto, es que «la transgresión de uno o más límites planetarios puede ser perjudicial o incluso catastrófico debido al riesgo de cruce de umbrales que desencadenarán un cambio ambiental no lineal y abrupto dentro de los sistemas de escala continental a escala planetaria». Esperando que los siguientes años la humanidad pueda operar con seguridad, se requieren conceptos que permitan cambiar el enfoque de gobernanza y gestión, «alejándonos del análisis esencialmente sectorial de límites al crecimiento, dirigido a minimizar las externalidades negativas, a la estimación del espacio seguro para el ser humano ${ }^{51}$.

Considerando la experiencia, el trabajo de diversos grupos de expertos y los desafíos mencionados previamente, el 25 de septiembre de 2016 el secretario general de la ONU invita a los representantes de los países miembros que se sumen a la iniciativa Transformar nuestro mundo: la agenda 2030 para el desarrollo sostenible ${ }^{52}$. Esta resolución establece una agenda con un enfoque interdisciplinario y universalista del desarrollo. Un concepto que va más allá del enfoque sectorial restrictivo de la Agenda del Milenio, concebido originalmente como objetivos para los países en desarrollo, a los cuales los países más ricos les ayudarían a lograr un bienestar.

El marco de referencia de los 17 ODS mantiene la disminución de la pobreza como eje del desarrollo, pero incluye como ingredientes fundamentales dos elementos: la participación explícita de las instituciones de gobierno y de la sociedad civil, y la protección y el cuidado del medio ambiente. El concepto de sostenibilidad se expande como una aspiración e invoca esferas como la prosperidad, la paz, las alianzas, las personas y el planeta. Para lograr los 17 ODS, pero particularmente las 169 metas que de ellos se derivan, es necesario construir y compartir nuevo conocimiento.

\section{Los Objetivos de Desarrollo del Milenio y la salud}

A diferencia de los ODM, en los ODS la salud desempeña un papel transversal. El diseño original establece que el objetivo 3 sea el específico para la salud, pues pretende "garantizar una vida sana y promover el bienestar de todos a todas las edades». Para promover la salud y el bienestar físico y mental, y prolongar la esperanza de vida de todas las personas, la ONU propone a los países que deben lograr:

- La cobertura universal de salud y el acceso a una atención médica de calidad, sin que nadie se quede fuera.

- Acelerar los avances conseguidos hasta la fecha en la reducción de la mortalidad neonatal, infantil y materna, poniendo fin a todas las muertes prevenibles para 2030.

- Garantizar el acceso universal a los servicios de salud sexual y reproductiva, incluidos los de planificación familiar, información y educación.

- Acelerar el ritmo de los progresos en la lucha contra la malaria, el VIH/sida, la tuberculosis, la hepatitis, el Ébola y otras enfermedades transmisibles y epidemias, incluso abordando la creciente resistencia a los antibióticos y el problema de las enfermedades desatendidas que afectan a los países en desarrollo.

- Establecer compromisos con la prevención y el tratamiento de las enfermedades no transmisibles, incluidos los trastornos conductuales, evolutivos y neurológicos, que constituyen un grave impedimento para el desarrollo sostenible ${ }^{52}$.

Sin embargo, como apuntan varios autores ${ }^{53}$, los objetivos relacionados con la salud son más de uno 
Tabla 2. Principales causas de muerte, muerte prematura, discapacidad y años de vida saludable perdidos en México en 2015

\begin{tabular}{|c|c|c|c|}
\hline \multicolumn{2}{|c|}{ Mortalidad (ajs edad) } & \multicolumn{2}{|l|}{$\begin{array}{c}\text { Años Perdidos por } \\
\text { Muerte Prematura } \\
\text { APMP }\end{array}$} \\
\hline & $\%$ & & $\%$ \\
\hline Cardiopatía Isquémica & 15.4 & Cardiopatía Isquémica & 10.0 \\
\hline Diabetes mellitus & 9.6 & Enf. Renal Crónica & 8.3 \\
\hline Enf. Renal Crónica & 9.4 & Diabetes mellitus & 7.9 \\
\hline Enf. Cerebrovascular & 6.2 & Cirrosis & 6.5 \\
\hline Cirrosis & 5.7 & Homicidios & 4.9 \\
\hline $\begin{array}{l}\text { Enf. Pulmonar obs. } \\
\text { Crónica }\end{array}$ & 4.9 & $\begin{array}{l}\text { Acc. de vehículo } \\
\text { de motor }\end{array}$ & 4.7 \\
\hline Enf. de Alzheimer & 4.7 & Anomalías Congénitas & 4.7 \\
\hline $\begin{array}{l}\text { Infecc. Respiratoria } \\
\text { baja }\end{array}$ & 3.6 & Enf. Cerebrovascular & 4.2 \\
\hline $\begin{array}{l}\text { Acc. de vehículo } \\
\text { de motor }\end{array}$ & 2.4 & $\begin{array}{l}\text { Infecc. Respiratoria } \\
\text { baja }\end{array}$ & 3.7 \\
\hline Homicidios & 2.3 & Pretérmino & 2.9 \\
\hline
\end{tabular}

\begin{tabular}{|c|c|c|c|}
\hline $\begin{array}{c}\text { Años Vividos } \\
\text { con discapacidad } \\
\text { AVD }\end{array}$ & \multicolumn{3}{|c|}{$\begin{array}{c}\text { Años de Vida } \\
\text { Saludable perdidos } \\
\text { AVISA }\end{array}$} \\
\hline & $\%$ & & $\%$ \\
\hline Diabetes mellitus & 10.0 & Diabetes mellitus & 8.7 \\
\hline $\begin{array}{l}\text { Lumbalgia } \\
\text { Hipoacusia rel }\end{array}$ & 6.6 & $\begin{array}{l}\text { Cardiopatía } \\
\text { Isquémica }\end{array}$ & 6.7 \\
\hline $\begin{array}{l}\text { Hipoacusia rel. } \\
\text { con la edad }\end{array}$ & 6.5 & Enf. Renal Crónica & 5.9 \\
\hline Depresión & 5.7 & Cirrosis & 4.1 \\
\hline Dolor de cuello & 4.7 & Anomalías & \\
\hline Migraña & 4.5 & Congénitas & 3.5 \\
\hline \multirow[b]{2}{*}{$\begin{array}{l}\text { Otras enf. Musculo } \\
\text { esqueléticas }\end{array}$} & & Homicidios & 3.1 \\
\hline & 3.3 & $\begin{array}{l}\text { Acc. de vehículo } \\
\text { de motor }\end{array}$ & 3.1 \\
\hline Ansiedad & 3.2 & Enf. Cerebrovascular & 2.7 \\
\hline $\begin{array}{l}\text { Problemas visuales } \\
\text { de refracción }\end{array}$ & 2.5 & $\begin{array}{l}\text { Hipoacusia rel. } \\
\text { con la edad }\end{array}$ & 2.4 \\
\hline Anemia ferrorpriva & 2.5 & Depresión & 2.2 \\
\hline
\end{tabular}

y también están presentes en los ODS 1, 2, 5, 6, 7 y 8 , lo cual arroja 17 metas y 43 indicadores. El concepto de salud que subyace a los ODS es amplio y consistente con el hecho de que el progreso en salud no depende exclusivamente del sistema de salud, sino que este debe ser abordado de manera multidisciplinaria e integral. Es aquí donde se encuentra el desafío para incorporar el abordaje planteado por los DSS.

\section{Las necesidades de salud y la respuesta social organizada en México}

Los ODS relacionados con la salud se expresan en metas que pretenden disminuir los eventos letales (tanto de enfermedades infectocontagiosas como de enfermedades crónicas no transmisibles), por un lado, y por otro buscar la participación de las instituciones del sistema de salud para ofrecer una respuesta social organizada a esas necesidades cambiantes de manera adecuada, de calidad y pertinente.

Una forma de ver los desafíos que enfrenta el sistema de salud es presentando las necesidades de salud del país, y para eso nos valemos de los resultados del estudio de la carga de la enfermedad, las lesiones y los factores de riesgo en el país en $2015^{54}$. En la tabla 2 se observa que, dependiendo del indicador seleccionado, las necesidades de salud

apremiantes son diferentes. Se sabe que, en México, el $78 \%$ de la carga de la enfermedad está asociado a padecimientos crónicos no transmisibles, y de ellos los principales son la diabetes mellitus (8.7\%), la cardiopatía isquémica $(6.7 \%)$ y la enfermedad renal crónica (5.9\%). Si solo tomamos la mortalidad, estos tres suman más de un tercio de las defunciones. Sin embargo, si observamos la tercera columna de la tabla 2, que resalta resultados no letales, aparecen padecimientos que están presentes en los ODS, como la depresión y otros problemas mentales y neurológicos. De hecho, un grupo de investigadores mexicanos ha publicado que, a pesar del progreso en salud alcanzado en los últimos 40 años, México atraviesa por una «transición disonante» debida sobre todo al incremento de muertes por homicidios, cirrosis hepática e insuficiencia renal crónica en adultos jóvenes, además de las incontrolables epidemias de diabetes mellitus, obesidad e hipertensión arterial en el resto de la población ${ }^{55}$. En contraparte, otro grupo de investigadores establece que los retos pueden alcanzarse siempre y cuando se logre: a) aumentar las intervenciones para promover estilos de vida saludable enfocadas a disminuir factores de riesgo, como los impuestos al tabaco y a las bebidas azucaradas, y la reducción del consumo de sal; b) contar con intervenciones en la atención primaria para prevención y detección temprana de enfermedades crónicas, además de un adecuado tratamiento 
y seguimiento de las enfermedades; y c) tener acceso a servicios hospitalarios de calidad para pacientes con enfermedades crónicas, así como servicios de urgencias eficientes ${ }^{56}$. A esto, Gutiérrez y García $^{57}$ reaccionan diciendo que es muy conveniente apoyar las estrategias institucionales siempre y cuando se garantice que tanto en las unidades médicas rurales como en los hospitales haya personal experimentado las 24 horas del día y los siete días de la semana, y no solo durante el día y entre semana, como ocurre comúnmente ${ }^{57}$.

Como todos los sistemas de salud del mundo, el mexicano tiene sus particularidades y estas pueden ser analizadas considerando su alcance (afiliación y acceso) y su capacidad de respuesta (cobertura efectiva). También pueden conocerse ciertos detalles contrastando los resultados que obtienen los subsectores que lo componen, público y privado, o por la contribución que ellos tienen al producto interior bruto (PIB) nacional considerando la generación de bienes y servicios relacionados con la salud a partir de las cuentas satélite en salud.

Un estudio reciente de la OCDE sobre el sistema de salud de México establece que «México necesita un sistema de salud que se enfoque en las necesidades de las personas, más que en los acuerdos históricos, y (sea) capaz de ofrecer atención preventiva y personalizada toda vez que cuente con un costo efectivo sostenible». Lo anterior lo basan en un diagnóstico pormenorizado tanto de la infraestructura como del desempeño del sistema, el cual caracterizan como «un sistema de salud fragmentado, con inequidades marcadas en el acceso y la calidad. Un sistema de salud ineficiente e indiferente a las necesidades de salud (que) impedirá que México logre la salud, la

Tabla 3. Producción de bienes y servicios del sector salud por tipo de régimen público y privado, 2015 (miles de millones de pesos a precios básicos de 2008 y porcentajes)

\begin{tabular}{|c|c|c|c|c|c|}
\hline & \multirow{2}{*}{$\begin{array}{l}\text { Total } \\
\text { MMP }\end{array}$} & \multicolumn{2}{|c|}{$\begin{array}{l}\text { Sector } \\
\text { privado }\end{array}$} & \multicolumn{2}{|c|}{$\begin{array}{l}\text { Sector } \\
\text { público }\end{array}$} \\
\hline & & MMP & $\%$ & MMP & $\%$ \\
\hline $\begin{array}{l}\text { Producción del sector } \\
\text { salud }\end{array}$ & 791.7 & 372.2 & 47.0 & 419.4 & 53.0 \\
\hline $\begin{array}{l}\text { Generación de bienes } \\
\text { y servicios }\end{array}$ & 672.1 & 252.8 & 37.6 & 419.2 & 62.4 \\
\hline $\begin{array}{l}\text { Producción de } \\
\text { bienes para el } \\
\text { cuidado a la salud }\end{array}$ & 119.6 & 119.4 & 99.8 & 0.2 & 0.2 \\
\hline
\end{tabular}

prosperidad y el progreso de lo que sin duda es capaz en los próximos años» ${ }^{58}$.

De acuerdo con la cuenta satélite del sector de salud de 2015 recientemente publicada por el INEGI ${ }^{59}$, en 2015 el Sistema de Salud mexicano contribuyó a la economía nacional con 976,000 millones de pesos (ajustados a pesos de 2008), lo que equivale al $5.4 \%$ del total del PIB del país. De esta cantidad, el $81 \%$ corresponde a la participación del sector público y privado, y el $19 \%$ lo aportó el trabajo no remunerado en los hogares para el cuidado a la salud. De los 792,000 millones de pesos con que contribuyó el sistema de salud (público y privado), el $22 \%$ correspondió a servicios hospitalarios, el $18 \%$ a servicios de atención ambulatoria, el $16 \%$ a comercio de bienes relacionados con la salud, el $9 \%$ a la compra de medicamentos, lentes y material de curación, y el $9 \%$ a la Administración pública de la salud. Es claro que la producción de bienes y servicios va dirigida a la atención médica y menos a la protección y promoción de la salud.

En la tabla 3 se puede apreciar que la producción de bienes y servicios del sector salud en 2015 alcanzó los 792,000 millones de pesos (a precios básicos).

$\mathrm{Al}$ analizar la producción de este sector de acuerdo con el tipo de régimen institucional, se observó que el sector público contribuyó con un $53 \%$, mientras que el sector privado lo hizo con un $47 \%$. La generación de bienes y servicios equivale al $85 \%$ de la producción del sector, y de ese monto, dos terceras partes provienen del sector público; en cambio, en la producción de bienes para el cuidado a la salud prácticamente todo proviene del sector privado. En ese mismo informe se reporta que la distribución del gasto de los hogares y del sector público es muy diferente (tabla 4). Por cada 100 pesos que los hogares

Tabla 4. Distribución del gasto de los hogares y del sector público en bienes y servicios de salud, 2015

\begin{tabular}{|c|c|c|c|}
\hline & Hogares & $\begin{array}{l}\text { Sector } \\
\text { Público }\end{array}$ & Total \\
\hline Total (MMP) & 447.1 & 491.8 & 938.9 \\
\hline Atención ambulatoria & 15.7 & 25.0 & 20.6 \\
\hline Hospitales & 7.0 & 51.4 & 30.3 \\
\hline Administración y salud pública & - & 19.6 & 10.3 \\
\hline Medicamentos* & 62.5 & - & 29.8 \\
\hline $\begin{array}{l}\text { Otros bienes para el cuidado } \\
\text { a la salud }\end{array}$ & 14.8 & 4.9 & 9.1 \\
\hline
\end{tabular}


Sector público

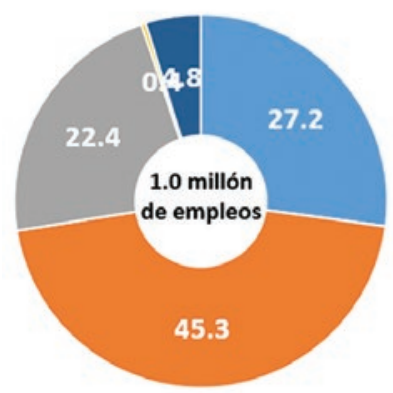

- Atención

ambulatoria

- Servicios hospitalarios

" Salud pública

= Auxiliar cuidado

salud

- Bienes de cuidados

de salud

\section{Sector privado}

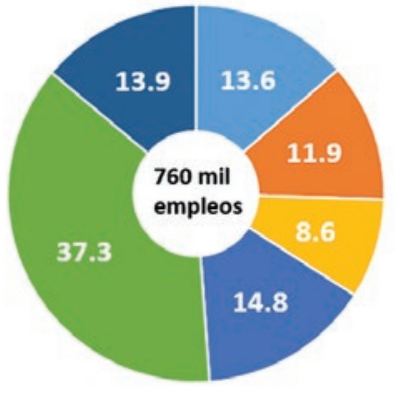

- Atención ambulatoria

- Servicios hospitalarios

- Salud pública

" Auxiliar cuidado salud

- Bienes de cuidados de salud

- Comercio de bienes relacionados con la salud

- Otros bienes de

cuidados de la salud

Figura 8. Distribución de los puestos de trabajo ocupados remunerados (puestos bajo una razón social) en el sector público y privado, México 2015. Fuente: INEGI, Cuenta Satélite de SS, 2015.

destinaron a la compra de bienes y servicios en salud, el $62.5 \%$ tiene que ver con la adquisición de medicamentos, el $15.7 \%$ con consultas médicas y el $7 \%$ con estancia en hospitales. En contraste, la mitad del gasto púbico se destina a hospitales (51\%), el $25 \%$ a atención ambulatoria y el $20 \%$ a la Administración en salud pública.

Según el INEGI, durante 2015 el sector salud registró 1,953,966 puestos de trabajo remunerados, lo que representa el $4.5 \%$ de los empleos remunerados de la economía en ese año. Si solo se consideran los que son dependientes de una razón social, el total asciende a 1.8 millones de empleos, de los cuales el $60 \%$ pertenecen al sector público y el $40 \%$ al privado. En la figura 8 se observa que la mayor parte del sector público se concentra en hospitales y servicios de atención ambulatoria, y en cambio, en el sector privado la mayor parte de los empleos son en el comercio de bienes relacionados con la salud y en la producción de bienes para el cuidado de la salud.

\section{Retos para el Sistema de Salud Mexicano ante los Objetivos de Desarrollo Sostenible}

Para la primera etapa (ODM), el gobierno de México informó de unos resultados aceptables. En nuestro país también se redujo la pobreza y mejoró el nivel educativo de los niños y las niñas. En materia de salud, los resultados no fueron como se esperaba; aunque alentadores por el avance en la disminución de la mortalidad en menores de 5 años o en la cobertura de vacunados contra el sarampión, aún quedan asuntos pendientes para la agenda de los ODS, como es el caso de la lenta disminución de la mortalidad materna o la baja disminución de la incidencia de tuberculosis ${ }^{60}$. A la pregunta de si el Sistema de Salud de México, que hemos presentado, está preparado para enfrentar los desafíos del siglo $\mathrm{XXI}$ y con ello encarar los ODS y rendir cuentas aceptables en 15 años, consideramos en primera instancia que no lo está y que se requieren acciones profundas de reorganización. A pesar de que se cuenta con un sistema de salud consolidado por su larga tradición e historia, este no ha logrado sincronizarse como debiera a las necesidades de salud de la población. Desafortunadamente sigue dominando la idea de que, en cualquier contexto, el sistema de salud es el responsable de todos los problemas de salud de la sociedad, cuando es claro que eso no es posible por razones políticas, financieras y conceptuales.

Desde el punto de vista financiero, es claro que nuestro país requiere reforzar su sistema de recolección de impuestos para mejorar el gasto público en salud. A pesar de que el gasto en salud se incrementó en números absolutos, en términos relativos es bajo, uno de los más bajos de los países de la OCDE y uno de los más altos en gastos privados y en gastos asignados a la Administración. Lo anterior obliga también a mejorar el uso de los recursos financieros públicos y su distribución.

Otro aspecto relevante es adecuar la organización de servicios a las cambiantes necesidades de salud de la población. Más allá de los compromisos internacionales adquiridos, el Sistema de Salud de México tiene el imperativo de fortalecer dos áreas: la atención 
primaria y la protección a la salud. Como se observa en la sección anterior, el modelo de atención a la salud en México está centrado en el hospital. Ahí se van los recursos humanos y financieros. Es un modelo reparador de la enfermedad y no de promoción de la salud. Centra sus esfuerzos en la atención de episodios de crisis y no en las personas. Es un modelo ideal para padecimientos agudos de corta duración, pero con serias dificultades para enfrentar los problemas crónicos que requieren continuidad y seguimiento individualizado.

El modelo de atención a la salud en México está centrado en incentivos dirigidos a reparar el daño y evitar la muerte, pero no a mantener la salud, que en el caso de los pacientes con enfermedades crónicas se reconoce como "controlados». Darle el giro al modelo de atención es el principal reto para el Sistema de Salud de México. Para eso, proponemos tres conceptos que son específicos para las necesidades de salud del siglo XXI y pueden articularse en la atención primaria:

\section{El tema de la salud ambiental}

Se analizan el proceso y los desafíos para la construcción de una agenda para el desarrollo sostenible común a todos los países y pueblos del mundo, a partir de aquellos desequilibrios ambientales asociados con una mayor carga de enfermedad y muerte evitables. Entre ellos, la contaminación del aire ambiente e intramuros, y la falta de acceso universal a agua segura, al saneamiento básico y a la exposición a sustancias químicas, en un contexto de cambios ambientales y climáticos a escala planetaria. Asimismo, se comentan algunos de los avances en la métrica aplicable a la salud ambiental. Se revisan, a partir de la perspectiva de los determinantes sociales y ambientales de la salud, algunas de las fortalezas y debilidades, así como algunas de las lecciones aprendidas derivadas de la implementación de los ODM y que podrían ser de utilidad para la puesta en práctica de los ODS recién aprobados. Finalmente, se comentan algunos de los retos pendientes de los programas de la salud ambiental en México, cuyo cumplimiento condiciona en gran medida el poder alcanzar en todo el país y de manera equitativa, efectiva y eficiente las metas incluidas en los ODS en la materia objeto de análisis.
- Cronicidad de los padecimientos, de los tratamientos y de las exposiciones.

- Continuidad de la atención, que como señalan Haggerty, et al. ${ }^{61}$ incluye tres dominios: continuidad en la información, en la provisión y en la organización de los servicios.

- Comorbilidad o presencia de más de un padecimiento en cada individuo.

Este modelo de atención que modifica la actual organización de los servicios de salud lo hemos denominado "de las tres C». Cuando se dice que debe ser un modelo Centrado en la persona, se refiere justo a lo que el Dr. Ignacio Chávez reconoce como el eje de la relación médico-paciente; la reciprocidad entre la Confianza del paciente hacia el médico y en general al sistema de salud, y la Conciencia que el médico y en general el personal de salud en cualquiera de sus funciones tiene con respecto a su obligación para con la salud de la población.

\section{Hacia un desarrollo sostenible}

El debate y el proceso para la construcción de una agenda común a todas las naciones y pueblos hacia un desarrollo sostenible no ha sido un ejercicio lineal. A lo largo de al menos siete décadas, este desafío ha sido muy dinámico y no exento de contradicciones. Desde una perspectiva internacional, este ejercicio ha transitado, en forma muy sucinta, en tres etapas sucesivas y por momentos sobrepuestas ${ }^{62}$.

La primera etapa nace con la creación de la ONU en 1945 y con la Declaración de los Derechos Humanos en 1948. La segunda etapa corresponde a la de las grandes conferencias temáticas mundiales ${ }^{\mathrm{V}}$, celebradas principalmente a partir de la

IV Entre ellas destacan la de Medio Ambiente Humano en Estocolmo, Suecia, en 1972; sobre la Atención Primaria de Salud en Alma Ata, antigua URSS, en 1978; la de Promoción de la Salud, en Ottawa, Canadá, en 1986; la Comisión Brundtland, en la ONU, en 1987; la de Medio Ambiente y Desarrollo, en Río de Janeiro, Brasil, en 1992; la de Población, en Pekín, China, en 1994; la de la Mujer, en El Cairo, Egipto, en 1995; la de Desarrollo Social, en Viena, Austria, en 1995; la COP 1 de Cambio Climático, en Berlín, Alemania, en 1995; la de Hábitat II, en Estambul, Turquía, en 1996; la de Alimentación, en Roma, Italia, en 1996; y la de Propiedad intelectual, en Doha, Qatar, en 2001. 
década de 1970, para dar paso a una tercera etapav caracterizada por la convergencia entre los ejes social, económico y ambiental como pilares del desarrollo sostenible. Esta tercera etapa se manifiesta con mayor claridad a partir del lanzamiento de los $\mathrm{ODM}^{63}$ y se fortalece con el informe El camino hacia la dignidad para $2030^{64}$ y con la adopción por la Asamblea General de la ONU en 2015 de la Agenda 2030 para el Desarrollo Sostenible ${ }^{65}$, que propone la agenda más ambiciosa y compleja hacia un genuino desarrollo sostenible. Esta agenda contempla 17 ODS con 169 metas de carácter integrado e indivisible, que abarcan las esferas económica, social y ambiental, incluyendo 230 indicadores globales que permitirán monitorear el progreso y el cumplimiento político de las metas establecidas. Oficialmente, esta nueva agenda entró en vigor el 1 de enero de $2016^{4}$.

El énfasis principal de los ODS recién aprobados es poner fin a la pobreza en el mundo, además de erradicar el hambre y lograr la seguridad alimentaria; garantizar una vida sana y una educación de calidad; lograr la igualdad de género; asegurar el acceso al agua y a la energía; promover el crecimiento económico sostenido y un ambiente resiliente, y adoptar medidas urgentes contra el cambio climático; así como promover la paz y facilitar el acceso a la justicia. El enorme desafío aglutinador de esta nueva agenda es que nadie se quede atrás. A pesar de que los ODS no son jurídicamente obligatorios, se espera que los gobiernos los adopten como propios y establezcan marcos nacionales para el logro de los 17 objetivos. Los países tienen la responsabilidad primordial del seguimiento y el examen de los progresos alcanzados en el cumplimiento de los ODS. No obstante, se reconoce que cada país enfrenta retos específicos en su tránsito hacia un desarrollo sostenible, y por tanto se refrenda el principio de que todos y cada uno de los Estados tienen soberanía plena sobre su riqueza, recursos y actividad económica ${ }^{66}$.

Alcanzar el futuro que queremos para todos requiere un alto grado de consistencia entre las políticas públicas globales, regionales, nacionales y subnacionales; también evitar que esta agenda se convierta

V Entre otras, la Conferencia sobre Desarrollo Sostenible, en Johannesburgo, Sudáfrica, en 2002; RIO+20, en Brasil, en 2012; sobre los Determinantes Sociales, en Río de Janeiro, Brasil, en 2012; sobre Salud en todas las políticas, en Helsinki, Finlandia, en 2013; la Cumbre sobre los Objetivos para el Desarrollo Sostenible, ONU/NY, EE.UU., en 2015 y 2016; y las COP sobre Cambio Climático en París, Francia, en 2015, y en Marrakech, Marruecos, en 2016. en una agenda meramente prescriptiva, reconociendo que no hay rutas únicas para el desarrollo. No hay una sola receta que sea válida para todos los países ${ }^{\vee}$. Por tanto, se requiere innovar la arquitectura y el funcionamiento de los mecanismos de gobernanza a todos los niveles de decisión, y garantizar la comparabilidad y el monitoreo en el tiempo y entre países. La Asamblea General de la ONU aprobó la recomendación hecha por la Comisión Estadística de Naciones Unidas que precisa las características técnicas y la forma de cálculo para cada uno de los indicadores propuestos ${ }^{67}$. Además, cada uno de los Estados seleccionará sus propias metas e indicadores nacionales complementarios a los ya establecidos en el ámbito global.

\section{Los desafíos en puerta}

Si bien el debate continúa en la dirección correcta y las propuestas apuntan hacia cómo lograr un mundo más equitativo, inclusivo, limpio, verde y próspero, en la práctica su implementación ha sido parcial y deficitaria. Los resultados obtenidos a la fecha distan del ideal. Se reconoce que la globalización ofrece grandes oportunidades. Sin embargo, sus beneficios se han distribuido de manera muy desigual ${ }^{68}$. Esta falta de equidad ha estimulado el crecimiento de movimientos de rechazo derivados de la creciente concentración de la riqueza ${ }^{69}$, y a la emergencia, sobre todo en algunos de los países más afluentes, de ideologías nacionalistas, xenofóbicas y proteccionistas que cuestionan la multilateralidad y las ventajas de una mayor integración e interdependencia global ${ }^{70}$. Durante la Conferencia de Río+20 se reconoció que la continuación de esta inercia no es una opción. Se requiere un cambio sustancial considerando que los determinantes del desarrollo están íntimamente interrelacionados, y que su abordaje, por tanto, requiere nuevos enfoques holísticos alineados con una serie de principios fundamentales, en particular los de los derechos humanos, la equidad y la sostenibilidad, además de que los objetivos y metas a cumplir estén inequívocamente orientados al logro de resultados?.

La experiencia acumulada indica que las tres dimensiones tradicionales (económica, social y ambiental) no bastan para alcanzar un verdadero desarrollo sostenible. Se requiere, además, que la paz y la seguridad mundial sean reconocidas como una cuarta dimensión, que contribuya a liberar a la humanidad de las carencias y el miedo, en momentos 
en que existen riesgos de una aceleración de la carrera armamentista con consecuencias imprevisibles $^{7}$. En todos y cada uno de los foros mundiales se han reconocido los importantes vínculos entre la salud y el desarrollo sostenible. Existe una amplia literatura que muestra cómo la estratificación social y las condiciones ambientales determinan los niveles de salud de las diversas poblaciones en cada uno de los países del planeta ${ }^{1}$. Entender y atender estas diferencias es crucial para construir sociedades más inclusivas, equitativas, económicamente productivas y sanas. De acuerdo con la OMS, una mejor salud es «una condición previa, un resultado y un indicador de las tres dimensiones del desarrollo sostenible» ${ }^{71}$. Este paradigma se refleja en la arquitectura y la fisiología de los ODS. Si bien en el objetivo 3 y sus nueve metas se concentran muchos de los temas relevantes de la salud, la verdadera expresión de la salud en el desarrollo se distribuye en cuando menos 47 de las metas incluidas en prácticamente todos los $\mathrm{ODS}^{72}$.

\section{De los Objetivos de Desarrollo del Milenio a los Objetivos de Desarrollo Sostenible}

Los desafíos para la implementación de los ODS son de grandes proporciones. Partiendo de las dificultades metodológicas y operacionales que representa alinear 17 objetivos, 160 metas y 230 indicadores, asegurando que las intervenciones a todos los niveles sean genuinamente convergentes y complementarias entre sí, a ello se suma el enorme reto financiero que esto conlleva y que depende de manera indiscutible de que los países desarrollados cumplan plenamente los compromisos acordados, transfiriendo en forma oportuna a los países más vulnerables entre el 0.15 y el $0.7 \%$ de su ingreso nacional bruto ${ }^{73}$. Sobre este asunto en particular prevalece un cierto escepticismo. Si bien entre los años 2000 y 2014 la asistencia oficial para el desarrollo por parte de los países desarrollados para la implementación de los ODM aumentó en un $66 \%$ en términos reales, alcanzando 135,200 millones de dólares, solo un limitado número de países desarrollados (Dinamarca, Luxemburgo, Noruega, Suecia y el Reino Unido) continuaron aportando el $0,7 \%$ del ingreso nacional bruto inicialmente pactado ${ }^{74}$.

Una de las mayores fortalezas de los ODM fue su número limitado de objetivos y metas, que además de concretos expresaban décadas de experiencia acumulada. Ello permitió priorizar políticas, intervenciones y un monitoreo basado en indicadores robustos enfocados a alcanzar los resultados previstos. Sin embargo, también se hicieron evidentes varias debilidades. El enfoque tecnológico top down adoptado fue reduccionista y vertical, contribuyendo a una mayor segmentación y fragmentación de los servicios de salud, favoreciendo además la disgregación de la propia agenda de salud. Debe destacarse que el proceso de consulta a la población sobre el contenido y el alcance de los ODM fue muy limitado, sumado a la decisión de que el monitoreo de resultados se focalizó en cifras promedio de carácter nacional, dejando en la penumbra a los niveles subnacionales y a grupos poblacionales en situaciones de vulnerabilidad, resultando por ende en una distribución inequitativa de los beneficios. Varios de los problemas importantes que afectan a la salud no fueron incluidos, en especial la rápida emergencia de las enfermedades crónicas. En general, se reconoció que hubo una limitada vinculación entre metas específicas de salud y otras iniciativas para el desarrollo'.

Desde su inicio, se hizo evidente que algunas metas no fueron realistas. Por ejemplo, el Objetivo 7, «Garantizar la sostenibilidad del medio ambiente», en su meta 7.C de reducir a la mitad, para el año 2015, el porcentaje de personas sin acceso sostenible al agua potable y a servicios básicos de saneamiento, en el acceso a fuentes mejoradas de agua la meta en todo el mundo se alcanzó 5 años antes de lo programado. Ello se explica en gran medida por la definición y el método de cálculo del indicador empleado, que a la letra dice: «disponibilidad de 20 litros per cápita por día a una distancia no superior a 1000 metros » ${ }^{75}$, y que a todas luces resultó poco ambicioso considerando las condiciones prevalentes en muchos países, en especial los de América Latina y el Caribe.

\section{La salud ambiental en debate}

Los pronósticos indican que a mediados del siglo XXI la población mundial será de aproximadamente 9100 millones (el 8.3\% en América Latina y el Caribe). Ante este crecimiento demográfico sin precedentes, la presión sobre el entorno natural no cesa, y en la medida en que un mayor número de habitantes se incorporan a la economía global se incrementa en forma más intensa la demanda de energía, alimentos, 
agua, madera, fibras y todo género de mercancías, cuyo consumo es inducido por un mercado voraz e insaciable, afectando irremediablemente a la resiliencia de los diferentes ecosistemas ${ }^{1}$. Casi la mitad de los bosques ya no existen, y las fuentes de agua subterráneas se merman rápidamente. La degradación de la tierra y la acidificación de los océanos están empeorando. La biodiversidad se ha visto enormemente afectada; las emisiones de dióxido de carbono se han incrementado, y la frecuencia y la gravedad de los desastres naturales desde la década de 1970 se ha quintuplicado?.

Una evaluación reciente señala que 15 de 24 $(60 \%)$ de los ecosistemas planetarios se están degradando de forma irreversible. En este contexto, los beneficios netos para el bienestar humano y el desarrollo económico han sido muy asimétricos. Mientras que minorías selectas han concentrado las mayores ventajas, las grandes mayorías no se han beneficiado de este proceso. De hecho, muchos habitantes han resultado perjudicados quedando atrapados en círculos viciosos de pobreza y marginación. Solo ahora se están poniendo de manifiesto los verdaderos costos y daños asociados con estas injusticias sociales y ambientales. Las desigualdades existentes y la lucha para acceder a los recursos naturales son determinantes clave de situaciones de conflicto, hambre, migración, inseguridad y violencia, que a su vez frenan el desarrollo sostenible. A menos que se dé un cambio radical en los patrones de consumo y de producción hacia modelos más racionales y sostenibles, el futuro será cada vez más incierto".

En lo concerniente a la salud ambiental, sobre todo en América Latina y el Caribe, tenemos una importante deuda acumulada. Aun reconociendo los avances en aspectos doctrinarios, metodológicos y de métricas aplicables a la salud ambiental, los servicios de salud continúan siendo predominantemente sectoriales y asistenciales, muy predeterminados por la cultura biomédica dominante. Si bien existe un marcado interés en promover acciones preventivas y los programas de promoción de la salud empezaron a encarar con mayor energía algunos de los problemas emergentes relacionados con el tabaquismo y el crecimiento epidémico de las enfermedades crónicas, sobre todo la obesidad y la diabetes, también otros problemas de salud tradicionales y emergentes derivados de los desequilibrios y de la contaminación ambiental empiezan a ser incluidos en las agendas hacia un desarrollo sostenible, en particular los que a continuación se comentan.

\section{Agua y saneamiento básico ${ }^{76}$}

Garantizar el acceso universal y sostenible a servicios de agua segura y a un saneamiento básico eficiente a poblaciones pobres en zonas marginales es parte de la agenda inconclusa. Sus daños a la salud aún son relevantes. El informe de 2015 sobre el Programa Conjunto de Monitoreo, Progresos en materia de Saneamiento y Agua, referente a la evaluación de los OMD, indica que entre 1990 y 2015 la población mundial que utiliza una fuente de agua mejorada pasó del 76 al 91\%. De los 2600 millones de personas que obtuvieron acceso a fuentes de agua potable mejorada, solo 1900 millones lo hicieron a través de agua suministrada por cañería hasta su propio hogar.

En todo el mundo, 147 países han cumplido con la meta del acceso a una fuente de agua potable, 95 países han alcanzado la meta de saneamiento y solo 77 países han cumplido ambas (México entre ellas). Sin embargo, una de cada tres personas de todo el mundo, el equivalente a 2400 millones, aún no tienen acceso a instalaciones de saneamiento, y 946 millones defecan al aire libre. En 2014, México registró una cobertura de agua en zonas urbanas (97\%) similar a la del resto de los países de América Latina y el Caribe. En poblaciones rurales fue solo del $92 \%$, pero aun así, la cobertura en México fue superior al $83 \%$ alcanzado como media en América Latina y el Caribe. Similar situación ocurre en cuanto al acceso a fuentes mejoradas de saneamiento; tanto en México como en el resto de los países de América Latina y el Caribe, la cobertura de las poblaciones urbanas fue del $88 \%$, en tanto que en las zonas rurales fue del 75 y el $63 \%$, respectivamente ${ }^{77}$. En México, a pesar de los avances, los problemas de escasez y contaminación del agua no han desaparecido. Por el contrario, en algunas zonas del país tienden a complicarse. Por ejemplo, el agotamiento de los mantos freáticos, sobre todo en el norte del país, favorece la contaminación por arsénico, y en las zonas petroleras, por hidrocarburos ${ }^{78}$.

\section{Contaminación del aire ambiental ${ }^{79}$}

Las principales fuentes de contaminación del aire incluyen el transporte ineficiente ${ }^{80}$, sobre todo en las 
zonas urbanas, la quema de residuos, las emisiones de las centrales eléctricas de carbón y las actividades industriales.

Datos recientes de la $\mathrm{OMS}^{16}$ señalan que aproximadamente el $92 \%$ de la población mundial vive en lugares donde los niveles de calidad del aire exceden los límites de exposición internacionalmente recomendados. Ello ocasiona unos tres millones de muertes al año, de las cuales cerca del $94 \%$ son por enfermedades no transmisibles, especialmente cardiovasculares, accidentes cerebrovasculares, enfermedad pulmonar obstructiva crónica (EPOC) y cáncer de pulmón. La contaminación del aire también se asocia con incrementos de las infecciones respiratorias agudas. La OMS estima que casi el $90 \%$ de las defunciones vinculadas a la contaminación del aire se producen en países de ingresos bajos y medios, afectando a poblaciones vulnerables predominantemente localizadas en países del sureste de Asia y las regiones del Pacífico occidental. En México, se estima que cada año ocurren aproximadamente 20,000 muertes atribuibles a la contaminación atmosférica, con un importante impacto en la morbilidad de la población ${ }^{81}$.

En fechas recientes, el tema de los efectos negativos en la salud derivados de la exposición a los contaminantes atmosféricos ha cobrado mayor relevancia. Además de los diferentes análisis realizados por la OMS, otras agencias internacionales, como el PNUMA ${ }^{82}$, el Banco Mundial| ${ }^{83}$, la OECD ${ }^{84}$, la UNICEF ${ }^{85}$ e instituciones académicas como el $\mathrm{IHME}^{86}$, entre otros, han contribuido al debate y a la búsqueda de soluciones de corto, mediano y largo plazo.

\section{Contaminación del aire de interiores ${ }^{87}$}

Datos de la OMS indican que unos 3000 millones de personas cocinan y calientan sus hogares con fuegos abiertos y cocinas en los que queman biomasa (madera, excrementos de animales o residuos agrícolas) y carbón, ocasionando 3,8 millones de defunciones prematuras anuales debidas a accidentes cerebrovasculares, cardiopatía isquémica y EPOC. Además, más del $50 \%$ de las muertes por neumonía en menores de 5 años son causadas por partículas inhaladas en interiores con aire contaminado. En México, aproximadamente 28 millones de habitantes en el país (el $90 \%$ en el área rural) utilizan combustibles sólidos, sobre todo leña, como su principal fuente de energía doméstica ${ }^{15}$.

\section{Exposición a sustancias químicas peligrosas $^{88}$}

Según la OMS, en 2012, cerca de 1,3 millones de vidas y 43 millones de años de vida ajustados por discapacidad (AVAD) se perdieron debido a la exposición a productos químicos. Sin embargo, estos datos reflejan de forma muy incompleta la verdadera magnitud del problema. La OMS estima que las intoxicaciones no intencionales causan 193,000 muertes cada año, la mayor parte de ellas prevenibles. Solo el $47 \%$ de los países tienen centros de toxicología establecidos. Como ejemplo, si se lograra abordar en forma eficiente la exposición al plomo se reduciría un $9.8 \%$ la pérdida de capacidad intelectual en menores de 5 años, un $4 \%$ la enfermedad cardiaca isquémica y un $4.6 \%$ los accidentes cerebrovasculares en las poblaciones expuestas. Aun así, muchos países carecen de normas o estas no han sido actualizadas.

Garantizar que todos los lugares de trabajo cumplan con las normas mínimas sanitarias y de seguridad contribuiría de manera significativa a reducir ciertos tipos de cáncer y neumopatías crónicas, así como lesiones y muertes prematuras. En México, diversos autores han abordado temas relacionados con la exposición crónica a compuestos orgánicos persistentes, metales pesados (plomo, manganeso), arsénico y algunos plaguicidas ${ }^{89}$. Debe señalarse que la explotación de hidrocarburos, entre otros, ha sido motivo de preocupación tanto por sus efectos en el ambiente como por sus riesgos para la salud. De acuerdo con estadísticas de la Procuraduría Federal de Protección al Ambiente (PROFEPA), cada año ocurren en el país alrededor de 600 emergencias ambientales asociadas con materiales y residuos peligrosos, principalmente petróleo y sus derivados (gasolinas, combustóleo, diésel), agroquímicos, gas LP y natural, entre otros. Muchas de estas emergencias fueron generadas por tomas clandestinas en los conductos de PEMEX ${ }^{15}$.

En México, dada la bastedad y complejidad del tema, no se dispone de un mapa de riesgos actualizado sobre la exposición humana a las sustancias químicas y la carga de enfermedad asociada, lo que limita la construcción de posibles escenarios y cursos de acción a escala nacional y regional. 


\section{Cambio climático ${ }^{90}$}

Cada día se consolida la evidencia de que el clima mundial está cambiando debido a causas antropogénicas. Este cambio afecta de manera significativa a la salud humana. Según la OMS, se prevé que entre 2030 y 2050 el cambio climático causará unas 250,000 defunciones adicionales cada año, por enfermedades transmitidas por vectores, enfermedades diarreicas y desnutrición, debido a la perturbación de la producción de alimentos, así como una mayor carga de enfermedad y muerte por fenómenos meteorológicos extremos. Se anticipa, además, que los países y las zonas con infraestructuras sanitarias más deficitarias serán los más afectados.

La OMS ${ }^{27}$ estima que, entre los años 2000 y 2030, los costos financieros para la atención de los daños directos a la salud (excluyendo los costos en los sectores determinantes para la salud, como la agricultura, el agua y el saneamiento) se situarán entre 2000 y 4000 millones de dólares anuales. De acuerdo con el Banco Mundial ${ }^{91}$, México es uno de los países más vulnerables ante el fenómeno climático: el $15 \%$ de su territorio, el $68 \%$ de su población y el $71 \%$ de su economía están expuestos a las consecuencias adversas relacionadas con el clima.

México fue uno de los primeros países en presentar su estrategia de largo plazo para reducir en un $50 \%$ su emisión de gases de efecto invernadero para el año 2050, tomando como base su medición del año 2000. En términos de mitigación, estableció como sus metas prioritarias la disminución en un $22 \%$ de sus emisiones de gases de efecto invernadero y en un $51 \%$ las de carbono negro para el año 2030. En cuanto a la adaptación al cambio climático, la meta es reducir la vulnerabilidad en 160 municipios; fortalecer las capacidades de las comunidades locales; incrementar las acciones de protección y restauración de ecosistemas; lograr la tasa cero en desforestación, además de generar e implementar sistemas de prevención y alerta temprana ante eventos hidrometeorológicos extremos ${ }^{92}$.

En México, en materia de salud, los estudios relacionados con el cambio climático se han enfocado principalmente en el análisis de la vulnerabilidad de poblaciones y las posibles variaciones en los comportamientos de enfermedades transmitidas por vectores; sobre sus interacciones con contaminantes atmosféricos; el incremento de enfermedades infecciosas, principalmente diarreicas, y los efectos agudos relacionados con golpes de calor y los riesgos asociados con el incremento en el número y la intensidad de fenómenos hidrometeorológicos adversos ${ }^{93}$.

Incluso tras la recién aprobada Convención Marco de las Naciones Unidas sobre Cambio Climático en 2015, durante la 21 Conferencia de las Partes (COP21) celebrada en París, Francia, su implementación no está exenta de dificultades. La nueva Administración de los EE.UU. (el mayor productor de gases con efecto invernadero del planeta) favorece el movimiento que niega las causas antropogénicas del cambio climático, y por tanto se anticipa que obstaculice la puesta en práctica de los acuerdos globales recién suscritos. A pesar de ello, se espera que varios de los estados de la Unión Americana sigan adelante con sus planes de reducir el uso de combustibles fósiles, estimulados tanto por las ventajas ambientales previstas como por el auge económico derivado de la puesta en práctica de nuevas tecnologías verdes ${ }^{94}$.

\section{Salud ambiental infantil}

Todos los niños necesitan entornos saludables, seguros y protectores para garantizar su bienestar, crecimiento y desarrollo normales. Globalmente, en torno a un tercio de los 6,6 millones de defunciones anuales de menores de 5 años se debe a causas y enfermedades relacionadas con el medio ambiente. Los factores de riesgo ambientales suelen actuar juntamente con condiciones económicas y sociales adversas. Las guerras, la pobreza y la malnutrición agravan sus efectos $^{95}$. En México se ha creado la Red de Salud Ambiental Infantil ${ }^{96}$, que actualmente tiene presencia en Ciudad de México, Durango, Guanajuato, Morelos, San Luis Potosí y Yucatán, y se están formando otros grupos de trabajo en Chihuahua, Chiapas y Querétaro. Los principales temas objeto de estudio por parte de esta Red se han concentrado en torno a la exposición de los niños a sustancias químicas y metales pesados.

\section{La salud ambiental y su métrica}

La OMS, en 1993, definió la salud ambiental ${ }^{97}$ como aquella que "comprende los aspectos de la salud humana, incluida la calidad de vida, que son determinados por factores físicos, químicos, biológicos, socioeconómicos y psicosociales, presentes en el medio ambiente». También se refiere a «la teoría y la 
práctica de evaluar, corregir, controlar y prevenir aquellos factores en el ambiente que pueden potencialmente afectar adversamente la salud de las generaciones presentes y futuras". En 2016, la OMS ${ }^{98}$ acotó la definición de riesgos ambientales para la salud como «todos los factores físicos, químicos y biológicos externos a las personas, así como todas las conductas relacionadas, excluyendo aquellos ambientes naturales que razonablemente no puedan modificarse».

En 2006, la $\mathrm{OMS}^{99}$, utilizando datos disponibles en 2002, estimó que alrededor del $24 \%$ de los AVAD y un $23 \%$ de las muertes prematuras en todo el mundo eran atribuibles a la exposición a riesgos ambientales evitables. Un tercio correspondían a la morbilidad en menores de 5 años, afectando de manera significativa a la capacidad de los servicios de salud, la estabilidad financiera, el crecimiento económico y la gobernanza en el sentido más amplio del concepto. Basándose en la metodología aplicada, se estimó en forma preliminar que en América Latina y México la mortalidad atribuible a causas ambientales fue del 17 y el $16 \%$, respectivamente ${ }^{100}$. En 2016, la OMS ${ }^{35}$, utilizando datos de 2012, estimó que 12,6 millones de muertes en todo el mundo eran por causas ambientales, y que cerca del $26 \%$ podrían ser evitadas. De ellas, las patologías que concentraron la mayor causalidad ambiental (en millones de muertes) fueron: 2.5 por accidentes cerebrovasculares, 2.3 por cardiopatía isquémica, 1.7 por traumatismos involuntarios (incluidos los accidentes de tránsito), 1,7 por cáncer, 1.4 por neumopatías crónicas, 0.846 por enfermedades diarreicas, 0.567 por infecciones respiratorias, 0.270 por afecciones neonatales y 0.259 por paludismo. Entre 2002 y $2012^{35}$, mientras que la mortalidad atribuible a causas ambientales en todo el mundo se redujo discretamente del 23.3 al $22.7 \%$, su distribución por grupos de enfermedades registró variaciones importantes. El mayor descenso fue del 31 al $20 \%$ en el grupo de enfermedades infecciosas, parasitarias, afecciones neonatales y nutricionales. En tanto, su contribución a las enfermedades crónicas no transmisibles se elevó del 17 al $22 \%$, mientras que las defunciones por causas externas se mantuvieron relativamente estables, pasando del 37 al $38 \%$.

Del total de las muertes atribuibles a causas ambientales, en la Región de las Américas, en 2012 se registraron aproximadamente $847,000(6.72 \%)^{35}$. A fines del año 2012 se divulgaron los resultados del Estudio de Carga Global de Enfermedad 2010
(ECGE 2010) $^{101}$, que analizó 67 factores de riesgo (ocho de ellos ambientales, incluyendo exposición a tabaco, fuentes de agua no mejoradas, fuentes de saneamiento no mejoradas, contaminación por partículas, contaminación de aire intramuros, contaminación atmosférica por ozono, radón en domicilio y exposición a plomo) en 21 regiones del mundo (seis de ellas de la Región de las Américas). La metodología se basó en la estimación y la comparación de los AVAD y su asociación causal con 291 diferentes patologías registradas en 1990 y 2010. Los principales resultados de este estudio sugieren que la contribución de los factores de riesgo a la carga de enfermedades y lesiones cambió sustancialmente, migrando de aquellos asociados sobre todo con las enfermedades transmisibles en niños a factores de riesgo vinculados con enfermedades no transmisibles en adultos.

En fechas más recientes, el Instituto de Estadísticas de Salud y Evaluación (IHME) ${ }^{102}$ analizó 33 de los 47 indicadores en salud (ocho relacionados con la salud ambiental) vinculados con los ODS según los datos disponibles entre 1990 y 2015 en 188 países. Este trabajo fue el producto de 1870 colaboradores de 124 países y tres territorios. Aun considerando algunas de sus limitaciones metodológicas, se espera que este tipo de bases de datos, así como las plataformas de análisis empleadas, contribuyan a establecer vías independientes más robustas para el monitoreo del progreso de los ODS y de las metas relacionados de manera directa e indirecta con la salud, incluida la salud ambiental. A pesar de los avances en las metodologías de análisis hechos durante los últimos años, es importante comentar que, en la mayoría de los estudios sobre mortalidad y carga de enfermedad atribuible a causas ambientales, las principales variables empleadas se han centrado en cuantificar el peso de los factores de riesgo físico y biológico, y en menor escala en los económicos asociados. El estudio de los determinantes sociales y conductuales como factores de riesgo se encuentra aún en fases muy incipientes.

\section{La salud ambiental en los Objetivos de Desarrollo Sostenible}

Los retos que la salud ambiental enfrenta son extensos, crecientes y acumulables. En lo tocante a Ios ODS, la estrategia seguida fue seleccionar aquellos factores de riesgo ambiental con un mayor 
impacto en la salud. En este contexto, se consideró relevante no abandonar la agenda inconclusa, sobre todo en el tema de acceso universal a agua segura y a un saneamiento básico. Se priorizaron, además, el reducir los índices de contaminación del aire y el disminuir la exposición a sustancias químicas peligrosas, que sin duda constituyen riesgos sustantivos a la salud humana. Por tanto, se acordó que dentro del ODS 3 , referente a «garantizar una vida sana y promover el bienestar para todos en todas las edades", la meta 3.9 aborde los problemas arriba descritos, señalando que "para el 2030 se reduzca sustancialmente el número de muertes y enfermedades producidas por productos químicos peligrosos y la contaminación del aire, el agua y el suelo». Para su monitoreo global se aprobaron los siguientes tres indicadores ${ }^{11}$ : Indicador 3.9.1, Tasa de mortalidad atribuible a la contaminación atmosférica doméstica y ambiental; Indicador 3.9.2, Tasa de mortalidad atribuible a la exposición a agua y al saneamiento básico inseguros y a la falta de higiene; e Indicador 3.9.3, Tasa de mortalidad atribuible a envenenamientos no intencionales. Además, otros asuntos prioritarios para la salud ambiental están presentes en otros ODS ${ }^{11}$. A manera de ejemplo, el abordaje de las sustancias químicas, aparte de la ya referida meta 3.9 en salud; este tema se encuentra presente en la meta 6.3 en cuanto a agua y saneamiento ${ }^{\mathrm{V}}$, y en la meta 12.4 en cuanto a producción y consumo sostenibles ${ }^{\mathrm{VII}}$.

\section{La salud ambiental en México' ${ }^{1}$}

Los primeros antecedentes de la política ambiental en México datan de los años 1940, con la promulgación de la Ley de Conservación del Suelo y el Agua. Al inicio de los años 1970 se decretó la Ley para Prevenir y Controlar la Contaminación Ambiental. En 1972, en el ámbito federal se crea la Subsecretaría de Mejoramiento del Ambiente como una

VI De aquí a 2030, mejorar la calidad del agua reduciendo la contaminación, eliminando el vertimiento y minimizando la emisión de productos químicos y materiales peligrosos, reduciendo a la mitad el porcentaje de aguas residuales sin tratar y aumentando considerablemente el reciclado y la reutilización sin riesgos a nivel mundial. Véase: http:// www.sela.org/media/2262361/agenda-2030-y-los-objetivos-de-desarrollo-sostenible.pdf

VII De aquí a 2020, lograr la gestión ecológicamente racional de los productos químicos y de todos los desechos a lo largo de su ciclo de vida, de conformidad con los marcos internacionales convenidos, y reducir significativamente su liberación a la atmósfera, el agua y el suelo, a fin de minimizar sus efectos adversos en la salud humana $y$ el medio ambiente. Véase: http://www.sela.org/media/2262361/agenda-2030-y-los-objetivos-de-desarrollo-sostenible.pdf dependencia de la Secretaría de Salud, cuyo enfoque fue eminentemente sanitarista. A partir de 1982, la política ambiental mexicana comenzó a adquirir una dimensión más integral y se reformó la Constitución para crear nuevas instituciones y bases jurídicas. En ese año se crea la Secretaría de Desarrollo Urbano y Ecología (SEDUE). Una década después, la SEDUE se transforma en la Secretaría de Desarrollo Social (SEDESOL) y se crean el Instituto Nacional de Ecología (INE) ${ }^{\text {VIII }}$ y la Procuraduría Federal de Protección Ambiental (PROFEPA). En 1994, SEDESOL se convierte en la Secretaría de Medio Ambiente, Recursos Naturales y Pesca (SEMARNAP), y en el año 2000, a partir de una visión más alineada con los conceptos de un desarrollo sostenible, la SEMARNAP se transforma en la Secretaría de Medio Ambiente y Recursos Naturales (SEMARNAT), que continúa vigente hasta nuestros días.

En 2001, en el sector salud se crea la Comisión Federal para la Protección contra Riesgos Sanitarios (COFEPRIS) ${ }^{1}$ como un órgano desconcentrado de la Secretaría de Salud, con autonomía técnica, administrativa y operativa, responsable del ejercicio de las atribuciones en materia de regulación, control y fomento sanitario, que incluyen una amplia gama de riesgos diferenciados y de gran complejidad, incluyendo los referentes a la prevención y el control de los efectos nocivos de los factores ambientales en la salud del hombre, la salud ocupacional y el saneamiento básico.

En forma paralela a los procesos de reestructuración de políticas y de las competencias jurídicas de diversas instituciones nacionales, la salud ambiental como disciplina académica también evolucionó. Si bien su crecimiento ha sido modesto, se han hecho algunos avances en la conformación y la consolidación de algunos grupos de investigación y docencia, que en diversas oportunidades han contribuido a la revisión y actualización de políticas, programas y normas en los ámbitos nacional y local ${ }^{15}$.

La transición epidemiológica en México ha sido desigual. A nivel subnacional persisten diferencias significativas en sus panoramas epidemiológicos asociados a las condiciones de vulnerabilidad social y ambiental prevalentes. Este proceso de transición ha sido el resultado de la intensidad y la calidad de múltiples intervenciones que han incidido sobre

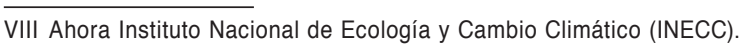


algunos de los factores de riesgo, entre ellos, los ambientales. Durante la etapa pretransicional, el principal énfasis se centró en la mejoría del saneamiento básico directamente asociado con las enfermedades transmitidas por el agua y por vectores, principalmente. Durante la fase transicional, la atención se concentró en la reducción de la exposición a contaminantes atmosféricos en ciudades, a químicos (plaguicidas y otros compuestos orgánicos persistentes) y a metales. En etapas más recientes, a los problemas ya mencionados se han agregado los derivados de los cambios ambientales a escala global ${ }^{15}$.

En México, como en otros países, las relaciones entre el hombre y el medio ambiente se han vuelto cada vez más complejas. Las políticas relacionadas con la salud ambiental no están circunscritas a los sectores de salud y ambiente únicamente; están dispersas en muchos más, incluyendo los de agricultura, energía, transporte y vivienda, entre otros. En lo general, la conciliación de los contenidos y alcances de estas políticas sectoriales es limitada y poco eficiente en función de las necesidades nacionales. A su vez, en lo referente a la salud ambiental, los diferentes programas e intervenciones, además de incompletos son fragmentados y tienden a ser más reactivos que proactivos, persistiendo deficiencias de coordinación entre los gobiernos federal, estatal y municipal. También es importante hacer notar que la interacción de las instancias públicas con los diversos sectores y grupos de la sociedad civil, académicos y productivos, es más coyuntural que estratégica y con una visión de corto a mediano plazo. Una posible y prometedora excepción es una mejor articulación de discursos e intereses en torno a promover acciones de mitigación y adaptación en torno a los efectos asociados con el cambio climático ${ }^{1,15}$. Entre otras, se destacan las iniciativas promovidas por la Ciudad de México ${ }^{103}$.

En México, la responsabilidad de dar seguimiento y coordinar la implementación de la Agenda 2030 para el Desarrollo Sostenible recae en la Presidencia de la República, con el apoyo del Comité Técnico Especializado del Sistema de Información de los Objetivos de Desarrollo del Milenio, responsable de coordinar los trabajos de carácter conceptual, metodológico, técnico y operativo ${ }^{104}$. A su vez, el Senado de México creó en septiembre de 2016 el Grupo de Trabajo para el Seguimiento Legislativo de los ODS, con el propósito de acompañar al gobierno mexicano en la implementación de la Agenda 2030, sobre todo en lo tocante a la transversalidad de las políticas públicas y sus implicaciones en asuntos presupuestales. En esta comisión han destacado como relevantes las cuestiones relativas al medio ambiente y al cambio climático ${ }^{105}$.

\section{Conclusiones y Recomendaciones del Simposio}

- Lograr en un plazo de 20 a 25 años índices iguales o cercanos a los de los países de mayor desarrollo, integrantes de la OCDE, para lo que es necesario incidir en las deficiencias en educación, vivienda, seguridad y condiciones sanitarias de las localidades, entre otras, con metas específicas por lograr, las cuales sean medidas en períodos trianuales o sexenales.

- Establecer una organización nacional presidida por el gobierno federal que en una sola línea de mando aglutine acciones conjuntas enfocadas a disminuir las desigualdades previamente mencionadas, en las que se incluyan las Secretarías de Salud, Economía, Desarrollo Social, Agricultura-Ganadería y Educación, y el sector privado, entre otras, con lo que seguramente podrá reforzarse el ahora programa Prospera, antes Oportunidades.

- Incorporar a sus contrapartes de los gobiernos estatales en las líneas de acción que se acuerden, asegurándose el cumplimiento de ellos.

- Empoderar a la población para que permita que las acciones se realicen en el menor tiempo posible.

- Es indispensable una firme, estrecha y simultánea colaboración entre los sectores público y privado del país.

- Ante las múltiples caras del embarazo adolescente en México y la complejidad del fenómeno, desde las barreras de acceso a servicios y a métodos anticonceptivos hasta la prevalencia de la violencia en todas sus expresiones, en especial a sus miembros más vulnerables y desprotegidos, por ser mujeres, por ser menores de edad, por vivir en situación de marginalidad educativa, económica y social, se deben identificar las causas multifactoriales y las consecuencias del fenómeno, a través de preguntas y módulos específicos en encuestas, registros y sistemas de información nacional; generar intervenciones diferenciales e integrales que impacten en los 
determinantes sociales de la salud adolescente y poner en acto políticas públicas integrales para reducir el embarazo en adolescentes, y en especial erradicar el embarazo en niñas. Estas comprenden desde el acceso a educación, incluida una educación sexual de calidad, el acceso a métodos anticonceptivos y servicios amigables, hasta una vida libre de violencia, el fortalecimiento y la implementación efectiva de leyes y normas que protejan los derechos y la salud sexual y reproductiva de nuestras niñas y adolescentes' ${ }^{\mathrm{IX}}$.

- El gran reto para el sistema de salud es transformarse, adecuarse y adaptarse a las necesidades de salud de la población. Por eso, la OCDE sugiere una reforma profunda del Sistema de Salud en México y le presenta cuatro recomendaciones al gobierno de México ${ }^{x}: 1$ ) incorporar una visión renovada para el cuidado de la salud en México, con una atención de calidad centrada en la persona; 2) definir un paquete de beneficios para todos los mexicanos, sin importar su empleo o estatus social, que sea equitativo y enfocado a la atención primaria; 3) unificar el enfoque fragmentado de financiamiento de la salud para mejorar la eficiencia y la equidad en el acceso; y 4) mantener la cobertura de aseguramiento en salud, independientemente de la situación laboral de las personas. El modelo de atención que debe enfrentar los desafíos de los ODS debe sumar acciones relacionadas con la generación de bienes públicos para todos los mexicanos.

- Hasta ahora, la narrativa dominante se queda, y hasta cierto punto se agota, en conferir mucha importancia a la prevención. Sin embargo, nuestra propuesta consiste en expandir este concepto e incorporar a la narrativa la Protección a la Salud. Estamos de acuerdo en el espíritu de las acciones preventivas, pero consideramos pertinente dirigir los esfuerzos a la elaboración de políticas saludables, que son la mejor expresión de las acciones de salud no personales.

- El desafío para el sistema de salud va más allá de los ODS, pero estos significan un gran

IX México, Gobierno de la Republica. Estrategia Nacional para la Prevención del Embarazo en Adolescentes. ENAPEA, México; 2015. Disponible en: https://www.gob.mx/cms/uploads/attachment/file/55979/ENAPEA 0215.pdf

$X$ OECD. OECD reviews of health Systems: Mexico 2016. Paris: OECD Publishing. Disponible en: http://dx.doi.org/10.17897/978964230491-en incentivo para reorganizar el modelo de atención y de financiamiento. La rendición de cuentas anualizada, así como el informe en 2030, darán cuenta del progreso alcanzado por el país en materia de salud.

- El deterioro ambiental continúa. Ante un planeta cada vez más enfermo, la premisa de alcanzar niveles de salud aceptables para todos se convierte en un reto crecientemente distante. La salud ambiental es un bien público que trasciende fronteras. Para seguir avanzando hacia un desarrollo sostenible, en un mundo crecientemente interdependiente, todo apunta a la urgente e impostergable necesidad de redefinir la arquitectura y el funcionamiento de la gobernanza de la salud ambiental a todos sus niveles, incluyendo el global, el nacional y el local. México enfrenta crecientes complejidades políticas, económicas, sociales y ambientales. Ante esta realidad, convendría analizar si la consolidación de la vigilancia y la protección de todos los posibles riesgos sanitarios en una sola institución (COFEPRIS) es lo más conveniente. Como parte del proceso evolutivo de los propios riesgos, en lo referente a la salud ambiental tal vez llegó el momento de replantear las capacidades y alcances de cada una de las dependencias del país, y evaluar si tienen la capacidad para responder con eficacia y eficiencia a los desafíos actuales y futuros. En varios de los países, sobre todo los emergentes (México incluido), los programas y las acciones relacionados con la prevención y el control de riesgos ambientales a la salud se han caracterizado por ser de alcance limitado, fragmentados, reactivos e incompletos, más remediales que preventivos. Los vínculos entre la salud ambiental y la agenda dominante de salud son débiles y periféricos. A menos que se logre superar estas limitaciones, el cumplimiento en México de los ODS en la materia podrá verse comprometido. México tiene la oportunidad de reducir la carga de enfermedad atribuible a causas ambientales; sobre todo, cerrar brechas entre poblacionales y territorios, promoviendo la salud ambiental como parte integral de las iniciativas que garanticen el acceso y la cobertura universal de salud.

- México tiene pendiente el desafío de definir en forma participativa y transparente las metas y los indicadores nacionales y subnacionales que complementen de manera realista a los ya 
establecidos en los ODS. La rendición de cuentas, prioritariamente a la población, representa una deuda pendiente. Un correcto y oportuno monitoreo de los indicadores para la medición de Ios ODS permitirá verificar si los discursos prometedores se están convirtiendo en acciones y resultados concretos.

\section{Bibliografía}

1. United Nations, Department of Economic and Social Affairs. The Millennium Development Goals Report 2015. New York: Organización de las Naciones Unidas; 2015.

2. Boerma T, Mathers C, AbouZahr C, et al. Health in 2015: from MDGs, Millennium Development Goals to SDGs, Sustainable Development Goals. WHO; 2015

3. ONU Asamblea General. A/69/L.85. Proyecto de documento final de la cumbre de las Naciones Unidas para la aprobación de la agenda para el desarrollo después de 2015. (Temas 13 a) y 115). 12 de agosto de 2015.

4. World Health Organization. Closing the gap in a generation. Health equity through action on the social determinants of health. Final report of the Commission on Social Determinants of Health. Geneva: WHO 2008. p. 1-232.

5. Urbina FM, Gonzáles B. La importancia de los determinantes sociales de la salud en las políticas públicas. INSP-ANMM; 2012. p. 11-129.

6. UN Populations Division, World Population Prospects, the 2014 Revision, medium variant.

7. Rockström J, Steffen W, Noone K, et al. A safe operating space for humanity. Nature. 2009;461:472-5.

8. Raworth K. A doughnut for the anthropocene: humanity's compass in the 21st century. Lance-Planetary Health. 2017;1:e48-9.

9. Sachs JD. The age of sustainable development. Columbia University Press; 2015

10. World Economic Forum. The Global Risks Report 2016, 11th ed. Published by the World Economic Forum within the framework of The Global Competitiveness and Risks Team.

11. Whitmee S, Haines A, Beyrer C. Safeguarding human health in the Anthropocene epoch: report of The Rockefeller Foundation-Lancet Commission on planetary health. Lancet. 2015;(386).

12. Marmot M, Friel S, Bell R, et al., on behalf of the Commission on Social Determinants of Health. Closing the gap in a generation: health equity through action on the social determinants of health. Lancet. 2008;372: 1661-9

13. PNUD. Panorama general. Informe sobre desarrollo humano 2015. Trabajo al servicio del desarrollo humano. Nueva York: Programa de las Naciones Unidas para el Desarrollo; 2015.

14. Solar O, Irwin A. A conceptual framework for action on the social determinants of health. Discussion paper for the Commission on Social Determinants of Health. Geneva: WHO; 2007.

15. $62^{\mathrm{a}}$ Asamblea Mundial de la Salud. (WHA62/14) Resolución EB124.R6. Recomendaciones de la Comisión sobre Determinantes Sociales de la Salud. 22 de mayo de 2009.

16. OMS. Declaración política de Río y sus recomendaciones. Conferencia Mundial sobre los Determinantes Sociales de la Salud. Río de Janeiro, Brasil, 19-21 de octubre de 2011.

17. Human Development Report 2014. Sustaining human progress: reducing vulnerability and building resilience. Published for the United Nations Development Programme (UNDP); 2014.

18. Consejo Nacional de Evaluación de la Política de Desarrollo Social. Informe de pobreza en México, 2014.

19. Consejo Nacional de Evaluación de la Política de Desarrollo Social. Diagnóstico de los objetivos e indicadores de los planes derivados del Plan Nacional de Desarrollo 2013-2018. México: CONEVAL; 2015.

20. Transforming our world: the 2030 agenda for sustainable development New York (NY): United Nations; 2015. Disponible en: https://sustainabledevelopment.un.org/post2015/transformingourworld

21. Urbina M. Los determinantes sociales de la salud y de la equidad en salud. Documento de postura. Academia Nacional de Medicina. Intersistemas editores/CONACYT; 2017

22. Therborn G. The killing fields of inequality. Polity Press; 2013.

23. Pobreza infantil en América latina y el Caribe. CEPAL Unicef, diciembre 2010. Las privaciones que sufren los niños: examen de los derechos infantiles incumplidos. Disponible en: http://www.unicef.org/lac/Libro-pobreza-infantil-America-Latina-2010(1)
24. Wilkinson R, Marmot M, Social determinants of health: the solid facts. 2nd ed. Den mark: WHO, 2006. Disponible en: http://www.euro.who.int/ data/assets/pdffile/0005/98438/e81384

25. Organización Mundial para la Salud. Subsanar las desigualdades en una generación: alcanzar la equidad sanitaria actuando sobre los determinantes sociales de la salud. Ginebra, Suiza: OMS; 2009. Disponible en: http://www.who.int/social_determinants/final_report/csdh_finalreport 2008

26. UNICEF. Child poverty in perspective: an overview of child well-being in rich countries. Innocenti Report Card 7, 2007. UNICEF Innocenti Research Centre, Florence. Disponible en: http://www.unicef-irc.org/publications/pdf/rc7

27. La infancia cuenta en México, 2006. Red por los derechos de la infancia en México. México. Disponible en: http://www.infanciacuenta.org/08publicaciones.html

28. La infancia cuenta en México, 2011. Red por los derechos de la infancia en México. Disponible en: http://www.derechosinfancia.org.mx/ICM2011_ librodedatos

29. Oficina de la Presidencia de la República. Los Objetivos de Desarrollo del Milenio en México. Informe de avances 2015. Primera edición: agosto 2015. p. 9-187.

30. Transforming our world: the 2030 agenda for sustainable development New York (NY): United Nations; 2015

31. Marmot M. WHO Commission on Social Determinants of Health Inequalities. Lancet. 2005;365:1099-104.

32. Programa de las Naciones Unidas para el Desarrollo: Objetivos de Desarrollo Sostenibles. Disponible en: http://www.undp.org/content/undp/ es/home/sustainable-development-goals.html

33. Naciones Unidas/CEPAL. Conferencia Regional sobre Población y Desarrollo de América Latina y el Caribe. Informe de avance del grupo de trabajo ad hoc encargado de elaborar una propuesta de indicadores para el seguimiento regional del consenso de Montevideo sobre población y desarrollo. Santiago, 16 de agosto de 2016; p. 11. Disponible en: http:// repositorio.cepal.org/bitstream/handle/11362/40468/S1600732_es.pdf?sequence $=1$ \&isAllowed $=y$

34. Naciones Unidas. Objetivos de Desarrollo del Milenio y más allá de 2015. Disponible en: http://www.un.org/es/millenniumgoals/

35. Oficina de la Presidencia de la República. Los ODM en México. Informe de avances 2015. México DF; 2015. Disponible en: http://200.23.8.225/ dm/Doctos/InfMex2015.pdf

36. Instituto Nacional de Estadística y Geografía (INEGI). Encuesta nacional de la dinámica demográfica 2014. Disponible en: http://www.beta.inegi. org.mx/proyectos/enchogares/especiales/enadid/2014/

37. Instituto Nacional de Salud Pública. Encuesta Nacional de Salud y Nutrición 2012. Resultados nacionales. Cuernavaca, Morelos, México; 2012. Disponible en: http://ensanut.insp.mx/informes/ENSANUT2012ResultadosNacionales.pdf

38. Consejo Nacional de Población. Situación de la salud sexual y reproductiva. México DF; 2016. Disponible en: https://www.gob.mx/cms/uploads/ attachment/file/170177/Situacion SS y R 2016.pdf

39. Allen-Leigh B, Villalobos-Hernández A, Hernández-Serrato $\mathrm{Ml}$, et al. Inicio de vida sexual, uso de anticonceptivos y planificación familiar en mujeres adolescentes y adultas en México. Salud Pública de México. 2013;55(Supl 2):S235-40.

40. Saavedra-Avendano A, Andrade-Romo Z, Rodriguez MI, et al. Adolescents and long-acting reversible contraception: lessons from Mexico. Matern Child Health J. 2016 May 5. [Epub ahead of print]

41. Secretaría de Salud. Subsistema de información sobre nacimientos. Disponible en: http://www.dgis.salud.gob.mx/contenidos/sinais/s_sinac.html

42. Secretaría de Salud. Dirección General de Información en Salud. Bases de datos nacidos vivos ocurridos. Certificado de nacimiento. Disponible en: http://www.dgis.salud.gob.mx/contenidos/basesdedatos/std_nacimientos_gobmx.html

43. Schiavon R, Valencia-Rodríguez JA. Adolescentes invisibles: embarazo en mujeres menores de 15 años. XV Congreso de Investigación en Salud Pública. Evidencia para la cobertura universal y efectiva. Cuernavaca, Morelos, México: Instituto Nacional de Salud Pública; 2013. Libro de resúmenes: abstract C247, p. 95-6.

44. Instituto Nacional de las Mujeres, DGTP, DSSPAS y EVCM. ESTUPRO Legislación Penal en las Entidades Federativas, México s/f. Disponible en: http://vidasinviolencia.inmujeres.gob.mx/sites/default/files/pdfs/cuadros_delitos/ESTUPRO.pdf

45. DOF 24/03/2016 Modificación de la Norma Oficial Mexicana NOM190-SSA1-1999, Prestación de servicios de salud. Criterios para la atención médica de la violencia familiar, para quedar como NOM046-SSA2-2005. Violencia familiar, sexual y contra las mujeres. Criterios para la prevención y atención, publicada el 16 de abril de 2009. Disponible en: http://www.dof.gob.mx/nota_detalle.php?codigo $=5430957 \&$ fecha $=24 / 03 / 2016$

46. UNFPA. Maternidad en la niñez. Enfrentar el reto del embarazo en adolescentes. El estado de la población mundial 2013. Fondo de Población de las Naciones Unidas, New York, Estados Unidos de América. 
Disponible en: https://www.unfpa.org/sites/default/files/pub-pdf/ESSWOP2013.pdf

47. México, Gobierno de la República. Estrategia Nacional para la Prevención del Embarazo en Adolescentes ENAPEA. México; 2015. Disponible en: https://www.gob.mx/cms/uploads/attachment/file/55979/ ENAPEA_0215.pdf

48. ONU. Declaración del Milenio. A/RES/55/, 2 de septiembre de 2000. Disponible en: http://www.un.org/spanish/milenio/ares552.pdf consultado el 2 de marzo de 2017

49. ONU. Road map towards the implementation of the United Nations MiIlennium Declaration. A/56/326, 5 de septiembre de 2011. Disponible en: http://www.un.org/documents/ga/docs/56/a56326.pdf

50. ONU. Objetivos de Desarrollo del Milenio: Informe de 2015. (Consultado el 3 de marzo de 2017.) Disponible en: http://www.un.org/es/millenniumgoals/pdf/2015/mdg_2015_s_summary_web.pdf

51. Rockström J, Steffen W, Noone K, et al. Planetary boundaries: exploring the safe operating space for humanity. Ecology and Society. 2009;14(2).

52. ONU. Transformar nuestro mundo: la Agenda 2030 para el desarrollo sostenible. A/70/L.1. (Consultado el 3 de marzo de 2017.) Disponible en: http://www.un.org/ga/search/view_doc.asp?symbol=A/70/L.1\&Lang=S

53. Lim S, Allen K, Bhutta Z, et al. Measuring the health-related Sustainable Development Goals in 188 countries: a baseline analysis from the Global Burden of Disease Study 2015. Lancet. 2016;388:1813-50.

54. Institute for Health Metrics and Evaluation (IHME). GBD Compare Data Visualization. Seattle, WA: IHME, University of Washington; 2016. (Consultado en marzo de 2017.) Disponible en: http:// vizhub.healthdata.org/ gbd-compare

55. Goméz-Dántes H, Fullman N, Lamadrid-Figueroa H, et al. Dissonant health transitions in the states of Mexico, 1990-2013: a systematic analysis for the Global Burden of Disease Study 2013. Lancet. 2016;388:2386-402.

56. González-Pier E, Barraza-Llorens M, Beyeler N, et al. Mexico's path towards the SDG for health. Lancet Global Health. 2016;4:e714-25.

57. Gutiérrez JP, García-Saizo S. No easy answer for how to tackle Mexico's health challenges. Lancet Global Health. 2016;4:e668-9.

58. OECD. OECD reviews of health Systems: Mexico 2016. Paris: OECD Publishing. Disponible en: http://dx doi org/10.17897/978964230491-en

59. INEGI. Cuenta Satélite del Sector Salud en México, 2015. (Consultado en marzo de 2017.) Disponible en: http://www.inegi.org.mx/est/contenidos/proyectos/cn/salud/default.aspx

60. Presidencia de la República. Los Objetivos de Desarrollo del Milenio. Informe de avances 2015. México DF. Disponible en: http://200.23.8.225/ odm/Doctos/InfMex2015.pdf

61. Haggerty JL, Reid RJ, Freeman GK, et al. Continuity of care: a multidisciplinary review. BMJ. 2003;327:1219.

62. Finkelman J, Galvao L, Henao S. Environmental health governance in Latin America and the Caribbean. En: Galvao L, Finkelman J, Henao S, editors. Environmental and social health determinants of health. Washington: PAHO/WHO; 2016. Disponible en: http://paltex.paho.org/Publication/Index?publicationld=046c7d66-77c8-42c6-bc59ff6247a04f

63. Naciones Unidas. Asamblea General 55/2. Declaración del Milenio A/54/L.81/Rev.1. Cumbre del Milenio de las Naciones Unidas. $13 \mathrm{de}$ septiembre de 2000. Disponible en: http://www.cinu.mx/minisitio/ODM8/ docs/Declaraci\%C3\%B3n\%20del\%20Milenio.pdf

64. Naciones Unidas. Asamblea General. Sexagésimo noveno período de sesiones. Temas 13 a) y 115 . El camino hacia la dignidad para 2030 acabar con la pobreza y transformar vidas protegiendo el planeta. Informe de síntesis del Secretario General sobre la Agenda de Desarrollo Sostenible después de 2015. 4 de diciembre de 2014. Disponible en http://www.un.org/en/development/desa/publications/files/2015/01/SynthesisReportSPA.pdf

65. Naciones Unidas. Resolución aprobada por la Asamblea General el 25 de septiembre de 2015. Transformar nuestro mundo: la Agenda 2030 para el Desarrollo Sostenible. Disponible en: http://www.un.org/es/comun/docs/?symbol=A/RES/70/1

66. Naciones Unidas. La agenda de desarrollo sostenible. Disponible en: http://www.un.org/sustainabledevelopment/es/la-agenda-de-desarroIlo-sostenible/

67. United Nations. Department of Economic and Social Affairs. Statistics Division. SDG Indicators Metadata repository. Disponible en: http://unstats.un.org/sdgs/metadata/

68. Naciones Unidas. El futuro que queremos para todos. Nueva York; 2012 Disponible en: http://www.un.org/en/development/desa/policy/untaskteam_undf/unttreport_sp.pdf

69. OXFAM. Una economía al servicio del 1\%. Acabar con los privilegios y la concentración de poder para frenar la desigualdad extrema. Informe de OXFAM. 18 de enero de 2016. Disponible en: https://www.oxfam.org/ sites/www.oxfam.org/files/file_attachments/bp210-economy-one-percenttax-havens-180116-es 0.pdf

70. Foreign Affairs. Snapshot November 15, 2016. Global Trumpism. Disponible en: https://www.foreignaffairs.com/articles/2016-11-15/global-trumpism

71. OMS. La Conferencia Río + 20 declara que la salud es fundamental para el desarrollo sostenible. 22 de junio de 2012. Disponible en: http://www. who.int/mediacentre/news/statements/2012/rio20_20120622/es/
72. CEPAL. Agenda 2030 y los Objetivos de Desarrollo Sostenible: una oportunidad para América Latina y el Caribe. Mayo 2016. Disponible en: http://www.sela.org/media/2262361/agenda-2030-y-los-objetivos-de-desarrollo-sostenible.pdf

73. CEPAL. Agenda 2030 y los Objetivos de Desarrollo Sostenible. Una oportunidad para América Latina y el Caribe. 2016. Disponible en: http:// www.sela.org/media/2262361/agenda-2030-y-los-objetivos-de-desarrollo-sostenible.pdf

74. Naciones Unidas. Objetivos de Desarrollo del Milenio. Informe de 2015. Disponible en: http://www.un.org/es/millenniumgoals/pdf/2015/mdg-report-2015_spanish.pdf

75. Naciones Unidas. Grupo de las Naciones Unidas para el Desarrollo. Indicadores para el seguimiento de los objetivos de desarrollo del milenio. ST/ESA/STAT/SER.F/95. Nueva York, 2006. Disponible en: http:// unstats.un.org/unsd/publication/seriesf/Seriesf 95s.pdf

76. OMS. Agua, saneamiento y salud (ASS). Informe 2015 del PCM sobre el acceso a agua potable y saneamiento: datos esenciales. Disponible en: http://www.who.int/water_sanitation_health/monitoring/jmp-2015-keyfacts/es/

77. OPS. Situación de Salud en las Américas: Indicadores Básicos de Salud 2016. Disponible en: http://iris.paho.org/xmlui/handle/123456789/31288

78. Riojas-Rodríguez $\mathrm{H}$, Schilmann A, López-Carrillo $\mathrm{L}$, et al. La salud ambiental en México: situación actual y perspectivas futuras. Salud Pública Méx. 2013;55:638-49. Disponible en: http://bvs.insp.mx/rsp/articulos/articulo e4.php?id=002925

79. OMS. Calidad del aire ambiente (exterior) y salud. Nota descriptiva. Actualización de septiembre de 2016. Disponible en: http://www.who.int/ mediacentre/factsheets/fs313/es/

80. Cepeda M, Schoufour J, Freak-Poli R, et al. Levels of ambient air pollution according to mode of transport: a systematic review. Lancet Public Health. 2016; published Online November 25, 2016. Disponible en: http:// www.thelancet.com/pdfs/journals/lanpub/PIIS2468-2667(16)30021-4.pdf

81. Riojas H. Contaminación atmosférica y salud en la Zona Metropolitana del Valle de México. 27 de abril de 2016. Disponible en: http://www.senado.gob.mx/comisiones/distrito_federal/reu/docs/presentacion_ HRR 270416.pdf

82. PNUMA. XIX Reunión del Foro de Ministros de Medio Ambiente de América Latina y El Caribe. Decisión 8. Plan de Acción Regional sobre Contaminación Atmosférica. Los Cabos, México; 11-14 de marzo de 2014. Disponible en: http://www.pnuma.org/forodeministros/19mexico/ documentos/decisiones/Contaminacion_Atmosferica/Decision_Contaminacion_atmosferica.pdf

83. World Bank. Narain U, Sall C. Methodology for valuing the health impacts of air pollution: discussion of challenges and proposed solutions. June 2016. Disponible en: http://elibrary.worldbank.org/doi/ abs/10.1596/24440

84. OECD. The economic consequences of outdoor air pollution. June 2016. Disponible en: http://www.oecd.org/environment/the-economic-consequences-of-outdoor-air-pollution-9789264257474-en.htm

85. UNICEF. Limpiar el aire para los niños. Octubre 2016. Disponible en: http://www.dnicostarica.org/wp-content/themes/sahifa/Gacetillas/2016/ UNICEF22.pdf

86. IHME. Global burden of air pollution. Feb. 2016. Disponible en: http:// www.healthdata.org/infographic/global-burden-air-pollution

87. OMS. Contaminación del aire de interiores y salud. Nota descriptiva $\mathrm{N}^{\circ}$ 292. Febrero de 2016. Disponible en: http://www.who.int/mediacentre/ factsheets/fs292/es/

88. WHO. Public health impact of chemicals: knowns and unknowns. 2016. Disponible en: http://www.who.int/ipcs/publications/chemicals-public-health-impact/en/

89. Cortinas C. Disponible en: http://cristinacortinas.org/sustentabilidad/proposito-del-sitio-web/\#

90. OMS. La OMS insta a los países a proteger la salud contra el cambio climático. Declaración de la OMS de 17 de noviembre de 2015. Disponible en: http://www.who.int/mediacentre/news/statements/2015/climate-change/es/

91. Banco Mundial. Las dimensiones sociales del cambio climático en México. 2013. Disponible en: http://www.bancomundial.org/content/dam/ Worldbank/document/web\%20spa\%20mexico.pdf

92. INECC. México presentó en la COP 22 su estrategia de cambio climático al 2050. 17 de noviembre de 2016. Disponible en: http://www.gob. $\mathrm{mx} /$ inecc/prensa/mexico-presento-en-la-cop-22-su-estrategia-de-cambio-climatico-al-2050?idiom=es

93. Riojas $\mathrm{H}$. Escenarios de salud pública en México ante el cambio climático. 2013. Disponible en: http://www.pincc.unam.mx/congresonacional2013/documentos_descargables/PDF/pdf\%20ibero\%20puebla/RiojasRodriguezHoracio.pdf

94. New York Times. Editorial Board. States will lead on climate change in the Trump era. DEC. 26, 2016. Disponible en: http://www.nytimes. com/2016/12/26/opinion/states-will-lead-on-climate-change-in-the-trumpera.html?action=click\&pgtype=Homepage \&clickSource=story-heading \& module $=$ opinion-c-col-left-region\&region $=$ opinion $-c-c o l-l e f t-r e g i o n \& W T$. nav=opinion-c-col-left-region\&_r $r=0$ 
95. OMS. 10 datos sobre la salud ambiental del niño. Diciembre de 2014 Disponible en: http://www.who.int/features/factfiles/children_environmental_health/es/

96. Red ambiental infantil. México. Disponible en: http://saludambientalinfantil.org/

97. Ordoñez G. Salud ambiental: conceptos y actividades. Rev Panam Salud Publica. 2000;7(3). Disponible en: http://www.scielosp.org/scielo.php?script=sci arttext\&pid=S1020-49892000000300001

98. WHO. Preventing disease through healthy environments. A global assessment of the burden of disease from environmental risks. 2016. Disponible en: http://apps.who.int/iris/bitstream/10665/204585/1/9789241565196_ eng.pdf?ua $=1$

99. OMS. La exposición a riesgos ambientales provoca casi una cuarta parte de las enfermedades. Junio 2006. Disponible en: http://www.who. int/mediacentre/news/releases/2006/pr32/es/

100. WHO. Country profile of environmental burden of disease, Mexico. 2006 Disponible en: http://www.who.int/quantifying_ehimpacts/national/countryprofile/mexico.pdf?ua=1
101. Lim S, et al. A comparative risk assessment of burden of disease and injury attributable to 67 risk factors and risk factor clusters in 21 regions, 1990-2010: a systematic analysis for the Global Burden of Disease Study 2010. Lancet. 2012;380:2224-60.

102. GBD 2015 SDG Collaborators. Measuring the health-related Sustainable Development Goals in 188 countries: a baseline analysis from the Global Burden of Disease Study 2015. Lancet. 2016;388:1813-50.

103. Centro Virtual de Cambio Climático en la Ciudad de México. Disponible en: http://www.cvcccm-atmosfera.unam.mx/index.php

104. INEGI. Modificación del acuerdo de creación del Comité Técnico Especializado del Sistema de Información de los Objetivos de Desarrollo del Milenio para convertirlo en el Comité Técnico Especializado de los Objetivos de Desarrollo Sostenible. 2016. Disponible en: http://200.23.8.225/ odm/Doctos/AcuerdoCrea.pdf

105. Senado de la República Mexicana. Gaceta del Senado No. 4. Comisión Especial sobre Cambio Climático. Viernes, 9 de septiembre de 2016. Disponible en: http://www.senado.gob.mx/sgsp/gaceta/63/2/2016-09-09-1/ assets/documentos/Gaceta 04.pdf 